\title{
Outcome reporting from protocols of clinical trials of Coronavirus Disease 2019
}

\section{(COVID-19): a review}

Ruijin Qiu, ${ }^{1}$ Xuxu Wei, ${ }^{1} \quad$ Mengzhu Zhao, ${ }^{2}$ Changming Zhong, ${ }^{1}$ Chen Zhao, ${ }^{3}$ Jiayuan Hu, ${ }^{1}$ Min Li, ${ }^{4}$ Ya Huang, ${ }^{1}$ Songjie Han, ${ }^{1}$ Tianmai He, ${ }^{1}$ Jing Chen, ${ }^{5}$ Hongcai Shang ${ }^{1} *$

1. Key Laboratory of Chinese Internal Medicine of Ministry of Education and Beijing,

Dongzhimen Hospital, Beijing University of Chinese Medicine.

2. First Teaching Hospital of Tianjin University of Traditional Chinese Medicine.

3. Institute of Basic Research In Clinical Medicine, China Academy of Chinese Medical Sciences

4. Beijing University of Chinese Medicine Third Affiliated Hospital

5. Baokang Affiliated Hospital of Tianjin University of Traditional Chinese Medicine, Tianjin

China.

\section{*Corresponding author:}

1. Jing Chen

Postal address: 88th Yuquan Road, Nankai District, Tianjin, China, 300193

Tel: +8602227474998

Email: cjshcsyc@126.com

2. Hongcai Shang

Postal address: Hai Yun Cang on the 5th Zip, Dongcheng District, Beijing, China, 100700.

Tel: +8601084012510

Email: shanghongcai@foxmail.com

Word count: 1864 


\section{Objectives}

To examine heterogeneity of outcomes in protocols of clinical trials of Coronavirus Disease 2019 (COVID-19) and to identify outcomes for prioritization in developing a core outcome set (COS) in this field.

\section{Design}

This study is a review.

\section{Data sources}

Databases of ICMJE-accepted clinical trial registry platform were searched on February 14, 2020.

\section{Eligibility Criteria}

Randomized controlled trials (RCTs) and non-RCTs of COVID-19 were considered. Conditions of patients include common type, severe type or critical type. Interventions include traditional Chinese medicine (TCM) and Western medicine. We excluded trials that for discharged patients, psychological intervention and complications of COVID-19.

\section{Data extraction and synthesis}

The general information and outcomes, outcome measurement instruments and measurement times were extracted. The results were analysed by descriptive analysis.

\section{Results}

19 registry platforms were searched. A total of 97 protocols were included from 160 protocols. For protocols of TCM clinical trials, 76 outcomes from 16 outcome domains were reported, and almost half $(34 / 76,44.74 \%)$ of outcomes were reported only once; the most frequently reported outcome was time of SARS-CoV-2 RNA turns to negative. 27 (27/76, 35.53\%) outcomes were provided one or more outcome measurement instruments. 10 outcomes were provided one or more measurement time frame. For protocols of western medicine clinical trials, 126 outcomes from 17 outcome domains were reported; almost half $(62 / 126,49.21 \%)$ of outcomes were reported only once; the most frequently reported outcome was proportion of patients with negative SARS-CoV-2. 27 outcomes were provided one or more outcome measurement instruments. 40 $(40 / 126,31.75 \%)$ outcomes were provided one or more measurement time frame.

\section{Conclusion}

Outcome reporting in protocols of clinical trials of COVID-19 is inconsistent. Thus, developing a core outcome set is necessary.

Keywords: Outcomes; clinical trials, COVID-19; review. 
medRxiv preprint doi: https://doi.org/10.1101/2020.03.04.20031401; this version posted March 8, 2020. The copyright holder for this preprint

(which was not certified by peer review) is the author/funder, who has granted medRxiv a license to display the preprint in perpetuity.

All rights reserved. No reuse allowed without permission.

\section{Strengths and limitations of this study}

1. This review is the first to describe variation in outcomes, outcome measurement instruments and outcome measurement time reporting in clinical trials for Coronavirus Disease 2019 (COVID-19).

2. All the database of ICMJE-accepted clinical trial registry platform were searched, and randomized controlled trials and observational studies were considered.

4. The aim of this review was to provide a list of outcomes for clinical trials of COVID-19, both interventions of Traditional Chinese Medicine and western medicine were considered.

5. When the searching was conducted, no clinical trials were registered by countries out of China, so all of included protocols were from China. 
medRxiv preprint doi: https://doi.org/10.1101/2020.03.04.20031401; this version posted March 8, 2020. The copyright holder for this preprint (which was not certified by peer review) is the author/funder, who has granted medRxiv a license to display the preprint in perpetuity.

All rights reserved. No reuse allowed without permission.

\section{INTRODUCTION}

Since the severe acute respiratory syndrome coronavirus 2 (SARS-CoV-2) infection occurred in Wuhan, Hubei Province from December 2019, the disease, which was named as Coronavirus Disease 2019 (COVID-19) by World Health Organization (WHO) on February 12, 2020. According to the website of National Health Commission of the People's Republic of China (NHC-PRC), 77,658 confirmed cases have been reported from all areas of China until 0 o'clock, February 25, 2020. 27,323 cured patients discharged, 2,663 patients died [1]. On the website of WHO showed that 2559 confirmed cases have been reported in 33 countries out of China, 34 patients died at 10AM CET, February 252020 [2].

However, there is still no specific medicine for COVID-19 now. In China, the government encourages traditional Chinese medicine (herbal medicine, moxibustion, Baduanjin, etc.) to take an important role in clinical practice. The NHC-PRC and National Administration of Traditional Chinese Medicine (NATCM) have released the Version 6.0 of Diagnosis and Treatment Guideline for COVID-19 (informal version) on February 18, 2020 [3]. The guideline recommended general therapy methods, such as oxygen support, or trying to use alpha-interferon, Lopinavir/Ritonavir, Ribavirin, Chloroquine phosphate, Abidol, etc. For severe and critical type of disease, high flow nasal catheter oxygen therapy, invasive or non-invasive mechanical ventilation, extracorporeal membrane oxygenation (ECMO), plasma of survivors, glucocorticoid, plasma exchange or according to the patients' situation. The guideline also recommended TCM therapy methods, including herbal medicine formulas and proprietary Chinese medicine according to TCM syndromes, which are analyzed by clinical symptoms and signs through four methods of diagnosis: inspection, auscultation and olfaction, interrogation, and palpation.

At the same time, an increasing number of clinical trials are conducting. After searching some protocols of clinical trials from Chinese Clinical Trial Registry (ChiTCR) and ClinicalTrials.gov, we found that different researchers chose different outcomes. It is very important for clinical trials to provide evidence in treating COVID-19. However, the heterogeneity of outcomes make it impossible to conduct meta-analysis in the future, which may reduce the value of clinical trials and improve waste.

We are going to develop a core outcome set (COS) for clinical trials of COVID-19. The study have been registered in Core Outcome Measures in Effectiveness Trials (COMET) database [4]. The first clinical trial of COVID-19 was registered on January 23, 2020 [5]. When we registered the COS study, there were about 50 clinical trials registered [4]. On February 25, 2020, the number of registered trials increased to 297. Before we finish the COS, we believe that it is very important to draw researchers' attention to concern about outcomes in their research. So we conducted a review of outcome reporting from registered clinical trials of COVID-19. Because 
TCM and western medicine take the same role in the treatment of COVID-19 in China, so the review includes both interventions.

\section{METHODS}

\section{Search strategy}

All the databases of ICMJE-accepted clinical trial registry platform [6] were considered. Search terms for ChiCTR included "COVID-19”, "2019-novel Corona Virus (2019-nCoV)", "Novel Coronavirus Pneumonia (NCP)", "Severe Acute Respiratory Infection (SARI)", "Severe Acute Respiratory Syndrome - Corona Virus- 2 (SARS-CoV-2)”. Search terms for Netherlands National Trial Register (NTR) included "nCoV", "Coronavirus", "SARS”, "SARI", "NCP", “COVID”. Search terms for other databases included "2019-nCoV OR Novel Coronavirus OR New Coronavirus OR SARS-CoV-2 OR SARI OR NCP OR Novel Coronavirus Pneumonia OR COVID-19 OR Wuhan pneumonia”. The searching conducted on n February 14, 2020.

\section{Inclusion criteria}

1. The population should include conformed patients of COVID-19.

2. Patients' conditions include common type, severe type or critical type.

3. The interventions include any type of TCM therapy or western therapy.

4. The study types include randomized controlled trial (RCT) and observation study.

\section{Exclusion criteria}

1. Studies for discharged patients.

2. Studies for psychological intervention.

3. Studies for complications of COVID-19.

\section{Study identification}

Two reviewers (RQ and $\mathrm{XW}$ ) independently assessed all the registered protocols. Any disagreement was resolved by discussion.

\section{Date extraction}

Two reviewers (RQ and MZ) independently extracted information. The information included the primary investigators' name, study type, type of disease, primary sponsor, number of settings, sample size, population's age, course of treatment, interventions, outcomes, outcome definition/measurement instruments, measurement time frame. Any disagreement was resolved by discussion.

\section{Merging outcomes and grouping under outcome domains}

Two researchers (RQ and CZ) merged the overlapping outcomes according to the definition 
of outcomes independently. If the researchers did not provide definition of outcome, they discussed and achieved consensus if necessary. For example, "PaO2/FiO2", "oxygenation index", "oxygen index", "the difference of $\mathrm{PaO} 2 / \mathrm{FiO} 2$ between two groups" were aggregated as "PaO2/FiO2". Many protocols presented composite outcomes. If definitions were provided, or all of the single outcomes in the composite one can be measured in one test, it was listed in the review. If a single outcome which belongs to a composite outcome was reported by one or more protocols, the composite outcome was removed from the review. But when we conduct Delphi survey in further research, the composite outcome will be list to consult the participants' opinion.

After the original outcomes were aggregated, two researchers (RQ and CZ) grouped individual outcomes into the appropriate outcome domain together and achieved consensus. The taxonomy of outcome domains were developed by the researchers from COMET initiative [7].

\section{Statistical analysis}

The results were analysed by descriptive analysis.

\section{Patient and public involvement}

The COVID-19 is highly infectious. For the safety of patients and public, they were not involved in the design or planning of the study.

\section{RESULTS}

\section{Characteristics of literature}

In this review, a total of 160 protocols from 19 different clinical trials registry platforms were searched. After reading titles and study details, 63 non-relevant or ineligible study protocols were excluded. In the end, 97 eligible study protocols were included from ChiCTR and ClinicalTrials.gov. The searching results and inclusion numbers were shown in Table 1.

In the included protocols, 34 clinical trials were for TCM therapy and 63 clinical trials were for western medicine therapy. All of clinical trials will be conducted in China. These clinical trials include 75 RCTs (53 for western medicine and 22 for TCM medicine) and 22 non-RCTs (10 for western medicine and 12 for TCM medicine). The first registered clinical trial for western medicine was on January 23, 2020, while the first registered clinical trial for TCM medicine was on January 27, 2020. The general characteristics of the included protocols are shown in table 2 and table 3 .

According to the information of primary sponsor, we found that the clinical trials were registered from 13 different provinces of China. Researchers from Hubei province registered more clinical trials $(31 / 97,31.96 \%)$ than researchers from other provinces. The distribution of clinical trials is 
shown in Figure 1.

Table 1 The global registry of COVID-19 related clinical trials searching results and inclusion

\begin{tabular}{|c|c|c|c|}
\hline ICMJE-accepted clinical trials registry & Results & Inclusion & Official website \\
\hline \multicolumn{4}{|l|}{ WHO Primary Registries } \\
\hline $\begin{array}{l}\text { Australian New Zealand Clinical Trials Registry } \\
\text { (ANZCTR) }\end{array}$ & 0 & 0 & https://www.anzctr.org.au/ \\
\hline Brazilian Clinical Trials Registry (ReBec) & 0 & 0 & http://www.ensaiosclinicos.gov.br/ \\
\hline Chinese Clinical Trial Registry (ChiCTR) & $111 *$ & 77 & http://www.chictr.org.cn/index.aspx \\
\hline $\begin{array}{l}\text { Clinical Research Information Service (CRiS), } \\
\text { Republic of Korea }\end{array}$ & 0 & 0 & $\begin{array}{l}\text { http://cris.nih.go.kr/cris/en/use_guide/cris } \\
\underline{\text { introduce.jsp }}\end{array}$ \\
\hline Clinical Trials Registry - India (CTRI) & 0 & 0 & http://ctri.nic.in/Clinicaltrials/login.php \\
\hline $\begin{array}{l}\text { Cuban Public Registry of Clinical Trials } \\
\text { (RPCEC) }\end{array}$ & 0 & 0 & http://registroclinico.sld.cu/en/home \\
\hline EU Clinical Trials Register (EU-CTR) & 0 & 0 & https://www.clinicaltrialsregister.eu/ \\
\hline German Clinical Trials Register (DRKS) & 0 & 0 & https://www.drks.de/drks_web/ \\
\hline Iranian Registry of Clinical Trials (IRCT) & 0 & 0 & https://www.irct.ir/ \\
\hline ISRCTN & 0 & 0 & http://www.isrctn.com/ \\
\hline Japan Primary Registries Network (JPRN) & 0 & 0 & https://rctportal.niph.go.jp/en/ \\
\hline Lebanese Clinical Trials Registry (LBCTR) & 0 & 0 & http://lbctr.emro.who.int/ \\
\hline Thai Clinical Trials Registry (TCTR) & 0 & 0 & http://www.clinicaltrials.in.th/ \\
\hline The Netherlands National Trial Register (NTR) & $24 *$ & 0 & https://www.trialregister.nl/ \\
\hline Pan African Clinical Trial Registry (PACTR) & 0 & 0 & https://pactr.samrc.ac.za/Search.aspx \\
\hline Peruvian Clinical Trial Registry (REPEC) & 0 & 0 & https://ensayosclinicos-repec.ins.gob.pe/en/ \\
\hline \multicolumn{4}{|l|}{ Other Registries } \\
\hline ClinicalTrials.gov & $25^{*}$ & 20 & https://www.clinicaltrials.gov/ \\
\hline UMIN Clinical Trials Registry (UMIN-CTR) & 0 & 0 & https://www.umin.ac.jp/ctr/index/htm/ \\
\hline EudraCT & 0 & 0 & https://eudract.ema.europa.eu/index.html \\
\hline
\end{tabular}


Table 2 The characteristics of included protocols for TCM clinical trials

\begin{tabular}{|c|c|c|c|c|c|c|c|c|}
\hline Study ID & Study type & $\begin{array}{l}\text { Type of } \\
\text { disease }\end{array}$ & $\begin{array}{l}\text { Primary } \\
\text { sponsor }\end{array}$ & $\begin{array}{l}\text { Number of } \\
\text { settings }\end{array}$ & $\begin{array}{l}\text { Sample } \\
\text { size }\end{array}$ & $\begin{array}{l}\text { Population' } \\
\text { age (years) }\end{array}$ & Intervention & Number of outcomes \\
\hline Zhong N [8] & Non RCT & COVID-19 & $\begin{array}{l}\text { Guangdong } \\
\text { Province, } \\
\text { China }\end{array}$ & 21 & 400 & $18-75$ & $\begin{array}{l}\text { Group 1: Xue-Bi-Jing injection } \\
\text { Group 2: CT }\end{array}$ & $\begin{array}{l}\text { Primary outcomes: } 1 \\
\text { Secondary outcomes: } 14\end{array}$ \\
\hline Huang L [9] & Non RCT & $\begin{array}{l}\text { COVID-19 } \\
\text { (without } \\
\text { severe type) }\end{array}$ & Beijing, China & 1 & 60 & $\geq 18$ & $\begin{array}{l}\text { Group 1:TCM treatment } \\
\text { Group 2: TCM treatment and Lopinavir / } \\
\text { Ritonavir } \\
\text { Group3: Lopinavir / Ritonavir; }\end{array}$ & $\begin{array}{l}\text { Primary outcomes: } 1 \\
\text { Secondary outcomes: } 8\end{array}$ \\
\hline $\begin{array}{ll}\text { Liang } & \mathrm{T} \\
{[10]} & \end{array}$ & $\mathrm{RCT}$ & COVID-19 & Beijing, China & 1 & 42 & $\geq 18$ & $\begin{array}{l}\text { Group 1: TCM + CT } \\
\text { Group 2: CT }\end{array}$ & $\begin{array}{l}\text { Primary outcomes: } 1 \\
\text { Secondary outcomes: } 3\end{array}$ \\
\hline Liu Q [11] & RCT & $\begin{array}{l}\text { severe and } \\
\text { critical } \\
\text { COVID-19 }\end{array}$ & Beijing, China & 1 & 100 & Unclear & $\begin{array}{l}\text { Group 1: Conventional medicine + TCM } \\
\text { Group 2:western medical therapies }\end{array}$ & $\begin{array}{l}\text { Primary outcomes: } \\
\text { Secondary outcomes: } 7\end{array}$ \\
\hline Xia W [12] & OS & COVID-19 & $\begin{array}{l}\text { Hubei } \\
\text { Province, } \\
\text { China }\end{array}$ & 1 & 300 & Unclear & Group 1: according to guidelines & $\begin{array}{l}\text { Primary outcomes: } 1 \\
\text { Secondary outcomes: } 0\end{array}$ \\
\hline $\begin{array}{l}\text { Wang } \quad \mathrm{Y} \\
{[13]}\end{array}$ & RCT & $\begin{array}{l}\text { Common } \\
\text { type of } \\
\text { COVID-19 }\end{array}$ & Beijing, China & 2 & 120 & Unclear & $\begin{array}{l}\text { Group 1: TCM standard decoctions + CT } \\
\text { Group 2: basic western medical therapies }\end{array}$ & $\begin{array}{l}\text { Primary outcomes: } 2 \\
\text { Secondary outcomes: } 6\end{array}$ \\
\hline Li J [14] & Non RCT & COVID-19 & $\begin{array}{l}\text { Henan } \\
\text { Province, } \\
\text { China }\end{array}$ & 8 & 100 & Unclear & $\begin{array}{l}\text { Group 1: TCM syndrome differentiation } \\
\text { treatment }+ \text { CT } \\
\text { Group 2: CT }\end{array}$ & $\begin{array}{l}\text { Primary outcomes: } 2 \\
\text { Secondary outcomes: } 8\end{array}$ \\
\hline $\begin{array}{l}\text { Zhong } \mathrm{N} \\
{[15]}\end{array}$ & $\mathrm{RCT}$ & COVID-19 & $\begin{array}{l}\text { Hebei } \\
\text { Province, } \\
\text { China }\end{array}$ & 7 & 400 & $\geq 18$ & $\begin{array}{l}\text { Group 1: CT + low dose of Lianhua Qingwen } \\
\text { Group 2: CT + Lianhua Qingwen medium dose } \\
\text { Group 3: CT + high dose of Lianhua Qingwen } \\
\text { Group 4: CT }\end{array}$ & $\begin{array}{l}\text { Primary outcomes: } 1 \\
\text { Secondary outcomes: } 6\end{array}$ \\
\hline Yang Z [16] & OS & COVID-19 & $\begin{array}{l}\text { Guangdong } \\
\text { Province, } \\
\text { China }\end{array}$ & 1 & 72 & $18-75$ & Group 1: Tanreqing injection & $\begin{array}{l}\text { Primary outcomes: } 2 \\
\text { Secondary outcomes: } 8\end{array}$ \\
\hline $\begin{array}{l}\text { Zhang } \\
{[17]}\end{array}$ & RCT & $\begin{array}{l}\text { COVID-19 } \\
\text { (virus turned } \\
\text { negative after } \\
\text { treatment) }\end{array}$ & $\begin{array}{l}\text { Hubei } \\
\text { Province, } \\
\text { China }\end{array}$ & 1 & 100 & $18-70$ & $\begin{array}{l}\text { Group 1: TCM decoctions+basic western } \\
\text { medical therapies } \\
\text { Group 2: CT }\end{array}$ & $\begin{array}{l}\text { Primary outcomes: } 3 \\
\text { Secondary outcomes: } 1\end{array}$ \\
\hline
\end{tabular}




\begin{tabular}{|c|c|c|c|c|c|c|c|c|}
\hline Study ID & Study type & $\begin{array}{l}\text { Type of } \\
\text { disease }\end{array}$ & $\begin{array}{l}\text { Primary } \\
\text { sponsor }\end{array}$ & $\begin{array}{l}\text { Number of } \\
\text { settings }\end{array}$ & $\begin{array}{l}\text { Sample } \\
\text { size }\end{array}$ & $\begin{array}{l}\text { Population' } \\
\text { age (years) }\end{array}$ & Intervention & Number of outcomes \\
\hline $\begin{array}{ll}\text { Zheng } \quad \mathrm{C} \\
{[18]}\end{array}$ & RCT & $\begin{array}{l}\text { COVID-19 } \\
\text { (virus turned } \\
\text { negative after } \\
\text { treatment) }\end{array}$ & $\begin{array}{l}\text { Hubei } \\
\text { Province, } \\
\text { China }\end{array}$ & 1 & 100 & $18-70$ & $\begin{array}{l}\text { Group 1: shadowboxing + CT } \\
\text { Group 2: CT }\end{array}$ & $\begin{array}{l}\text { Primary outcomes: } 4 \\
\text { Secondary outcomes: } 1\end{array}$ \\
\hline Xia W [19] & $\mathrm{RCT}$ & $\begin{array}{l}\text { COVID-19 } \\
\text { (virus turned } \\
\text { negative after } \\
\text { treatment) }\end{array}$ & $\begin{array}{l}\text { Hubei } \\
\text { Province, } \\
\text { China }\end{array}$ & 1 & 100 & $18-70$ & $\begin{array}{l}\text { Group 1: Pulmonary rehabilitation+ CT } \\
\text { Group 2: CT }\end{array}$ & $\begin{array}{l}\text { Primary outcomes: } 2 \\
\text { Secondary outcomes: } 3\end{array}$ \\
\hline Xia W [20] & RCT & $\begin{array}{l}\text { Common } \\
\text { type of } \\
\text { COVID-19 }\end{array}$ & $\begin{array}{l}\text { Hubei } \\
\text { Province, } \\
\text { China }\end{array}$ & 1 & 100 & $18-70$ & $\begin{array}{l}\text { Group 1: TCM decoctions+ CT } \\
\text { Group 2: CT }\end{array}$ & $\begin{array}{l}\text { Primary outcomes: } 3 \\
\text { Secondary outcomes: } 5\end{array}$ \\
\hline Wen C [21] & RCT & $\begin{array}{l}\text { common or } \\
\text { severe type } \\
\text { of } \\
\text { COVID-19 }\end{array}$ & $\begin{array}{l}\text { Zhejiang } \\
\text { Province, } \\
\text { China }\end{array}$ & 1 & 140 & $14-80$ & $\begin{array}{l}\text { Group } 1 \text { (ordinary): CT } \\
\text { Group } 2 \text { (ordinary): TCM + CT } \\
\text { Group } 3 \text { (severe): CT } \\
\text { Group } 4 \text { (severe): TCM + CT }\end{array}$ & $\begin{array}{l}\text { Primary outcomes: } 3 \\
\text { Secondary outcomes: } 6\end{array}$ \\
\hline Xie C [22] & $\mathrm{RCT}$ & $\begin{array}{l}\text { Suspected } \\
\text { and } \\
\text { confirmed } \\
\text { diagnosis of } \\
\text { COVID-19 }\end{array}$ & $\begin{array}{l}\text { Sichuan } \\
\text { Province, } \\
\text { China }\end{array}$ & 1 & 400 & Unclear & $\begin{array}{l}\text { Group 1: TCM treatment }+\mathrm{CT} \\
\text { Group 2: CT }\end{array}$ & $\begin{array}{l}\text { Primary outcomes: } 4 \\
\text { Secondary outcomes: } 0\end{array}$ \\
\hline Xie C [23] & OS & $\begin{array}{l}\text { suspected } \\
\text { and } \\
\text { confirmed } \\
\text { diagnosis of } \\
\text { COVID-19 }\end{array}$ & $\begin{array}{l}\text { Sichuan } \\
\text { Province, } \\
\text { China }\end{array}$ & 1 & 200 & Unclear & Group 1: TCM treatment $+\mathrm{CT}$ & $\begin{array}{l}\text { Primary outcomes: } 13 \\
\text { Secondary outcomes: } 0\end{array}$ \\
\hline Wen C [24] & OS & COVID-19 & $\begin{array}{l}\text { Zhejiang } \\
\text { Province, } \\
\text { China }\end{array}$ & 1 & 1000 & Unclear & $\begin{array}{l}\text { Group 1: Integrated Traditional Chinese and } \\
\text { Western Medicine }\end{array}$ & $\begin{array}{l}\text { Primary outcomes: } 4 \\
\text { Secondary outcomes: } 5\end{array}$ \\
\hline Liu Q [25] & Non-RCT & $\begin{array}{l}\text { Common } \\
\text { type of } \\
\text { COVID-19 }\end{array}$ & Beijing, China & 5 & 60 & $\geq 18$ & $\begin{array}{l}\text { Group 1: Reduning injection }+ \text { CT } \quad \text { Group } \\
\text { 2: CT }\end{array}$ & $\begin{array}{l}\text { Primary outcomes: } 1 \\
\text { Secondary outcomes: } 5\end{array}$ \\
\hline
\end{tabular}




\begin{tabular}{|c|c|c|c|c|c|c|c|c|}
\hline Study ID & Study type & $\begin{array}{l}\text { Type of } \\
\text { disease }\end{array}$ & $\begin{array}{l}\text { Primary } \\
\text { sponsor }\end{array}$ & $\begin{array}{l}\text { Number of } \\
\text { settings }\end{array}$ & $\begin{array}{l}\text { Sample } \\
\text { size }\end{array}$ & $\begin{array}{l}\text { Population' } \\
\text { age (years) }\end{array}$ & Intervention & Number of outcomes \\
\hline $\begin{array}{ll}\text { Wang } & \text { D } \\
{[26]} & \end{array}$ & RCT & COVID-19 & $\begin{array}{l}\text { Hubei } \\
\text { Province, } \\
\text { China }\end{array}$ & 2 & 400 & $\geq 18$ & $\begin{array}{l}\text { Group 1: Low dose of Shuanghuanglian }+ \text { CT } \\
\text { Group 2: Medium dose of Shuanghuanglian }+ \\
\text { CT } \\
\text { Group 3: High dose of Shuanghuanglian + CT } \\
\text { Group 4: CT }\end{array}$ & $\begin{array}{l}\text { Primary outcomes: } 1 \\
\text { Secondary outcomes: } 6\end{array}$ \\
\hline $\begin{array}{l}\text { Zhang } \quad \mathrm{Z} \\
{[27]}\end{array}$ & OS & COVID-19 & $\begin{array}{l}\text { Guangdong } \\
\text { Province, } \\
\text { China }\end{array}$ & 1 & 100 & Unclear & $\begin{array}{l}\text { Group 1: Xinguan-1 formula }+ \text { CT } \\
\text { Group 2: CT }\end{array}$ & $\begin{array}{l}\text { Primary outcomes: } 2 \\
\text { Secondary outcomes: } 10\end{array}$ \\
\hline Xiao X [28] & RCT & COVID-19 & Beijing, China & 1 & 150 & $14-80$ & $\begin{array}{l}\text { Group 1: } \mathrm{TCM}+\mathrm{CT} \\
\text { Group 2: CT }\end{array}$ & $\begin{array}{l}\text { Primary outcomes: } 1 \\
\text { Secondary outcomes:5 } \\
\text { Other outcomes: } 4\end{array}$ \\
\hline $\begin{array}{l}\text { Zhang } \quad \mathrm{N} \\
\text { [29] }\end{array}$ & RCT & COVID-19 & $\begin{array}{l}\text { Anhui } \\
\text { Province, } \\
\text { China }\end{array}$ & 4 & 200 & $12-80$ & $\begin{array}{l}\text { Group 1: TCM } \\
\text { Group 2: CT }\end{array}$ & $\begin{array}{l}\text { Primary outcomes: } \\
\text { Secondary outcomes: } 0\end{array}$ \\
\hline Mao W [30] & OS & $\begin{array}{l}\text { suspected or } \\
\text { confirmed } \\
\text { COVID-19 }\end{array}$ & $\begin{array}{l}\text { Zhejiang } \\
\text { Province, } \\
\text { China }\end{array}$ & 9 & 350 & $18-85$ & 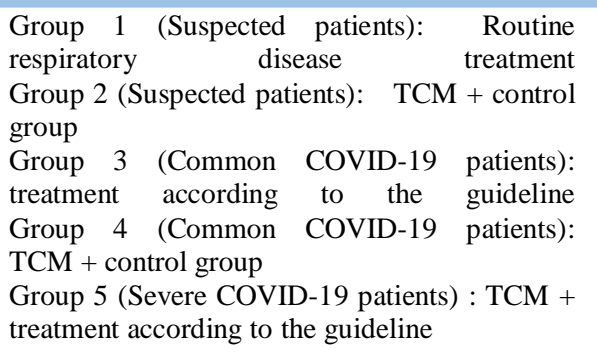 & $\begin{array}{l}\text { Primary outcomes: } 6 \\
\text { Secondary outcomes: } 4\end{array}$ \\
\hline Liu D [31] & $\mathrm{RCT}$ & COVID-19 & $\begin{array}{l}\text { Hubei } \\
\text { Province, } \\
\text { China }\end{array}$ & 1 & 120 & $\geq 18$ & $\begin{array}{l}\text { Group 1: Jinyebaidu granule }+\mathrm{CT} \\
\text { Group 2: } \mathrm{CT}\end{array}$ & $\begin{array}{l}\text { Primary outcomes: } 1 \\
\text { Secondary outcomes: } 1\end{array}$ \\
\hline $\begin{array}{l}\text { Huang L } \\
{[32]}\end{array}$ & $\mathrm{RCT}$ & $\begin{array}{l}\text { Common } \\
\text { type of } \\
\text { COVID-19 }\end{array}$ & Beijing, China & 1 & 408 & $18-75$ & $\begin{array}{l}\text { Group 1: } \mathrm{TCM}+\mathrm{CT} \\
\text { Group 2: CT }\end{array}$ & $\begin{array}{l}\text { Primary outcomes: } 1 \\
\text { Secondary outcomes: } 7\end{array}$ \\
\hline Lv D [33] & RCT & $\begin{array}{l}\text { Severe type } \\
\text { of } \\
\text { COVID-19 }\end{array}$ & $\begin{array}{l}\text { Zhejiang } \\
\text { Province, } \\
\text { China }\end{array}$ & 1 & 40 & $18-80$ & $\begin{array}{l}\text { Group 1: Babaodan + CT } \\
\text { Group 2: CT }\end{array}$ & $\begin{array}{l}\text { Primary outcomes: } 2 \\
\text { Secondary outcomes: } 0\end{array}$ \\
\hline
\end{tabular}




\begin{tabular}{|c|c|c|c|c|c|c|c|c|}
\hline Study ID & Study type & $\begin{array}{l}\text { Type of } \\
\text { disease }\end{array}$ & $\begin{array}{l}\text { Primary } \\
\text { sponsor }\end{array}$ & $\begin{array}{l}\text { Number of } \\
\text { settings }\end{array}$ & $\begin{array}{l}\text { Sample } \\
\text { size }\end{array}$ & $\begin{array}{l}\text { Population' } \\
\text { age (years) }\end{array}$ & Intervention & Number of outcomes \\
\hline $\begin{array}{ll}\text { Huang } & \mathrm{T} \\
{[34]} & \end{array}$ & RCT & $\begin{array}{l}\text { Severe type } \\
\text { of } \\
\text { COVID-19 }\end{array}$ & $\begin{array}{l}\text { Hubei } \\
\text { Province, } \\
\text { China }\end{array}$ & 3 & 160 & $18-80$ & $\begin{array}{l}\text { Group 1: Truncation and Torsion Formula }+ \\
\text { CT } \\
\text { Group 2: CT }\end{array}$ & $\begin{array}{l}\text { Primary outcomes: } 2 \\
\text { Secondary outcomes: } 7\end{array}$ \\
\hline $\begin{array}{l}\text { Zhang } \quad \text { W } \\
\text { [35] }\end{array}$ & Non-RCT & COVID-19 & $\begin{array}{l}\text { Shanghai, } \\
\text { China }\end{array}$ & 1 & 600 & $15-85$ & $\begin{array}{l}\text { Group 1: herbal medicine based on TCM } \\
\text { syndrome + CT } \\
\text { Group 2: Qing-Fei-Pai-Du decoction + CT } \\
\text { Group 3: Shu-Feng-Jie-Du capsuale + CT } \\
\text { Group 4: CT }\end{array}$ & $\begin{array}{l}\text { Primary outcomes: } 2 \\
\text { Secondary outcomes: } 6\end{array}$ \\
\hline $\begin{array}{l}\text { Zheng } \\
{[36]}\end{array}$ & $\mathrm{RCT}$ & COVID-19 & $\begin{array}{l}\text { Hubei } \\
\text { Province, } \\
\text { China }\end{array}$ & 6 & 160 & $\geq 18$ & $\begin{array}{l}\text { Group 1: Shenqi Fuzheng Injection }+\mathrm{CT} \\
\text { Group 2: CT }\end{array}$ & $\begin{array}{l}\text { Primary outcomes: } 1 \\
\text { Secondary outcomes: } 3\end{array}$ \\
\hline $\begin{array}{l}\text { Zheng } \\
{[37]}\end{array}$ & RCT & COVID-19 & $\begin{array}{l}\text { Hubei } \\
\text { Province, } \\
\text { China }\end{array}$ & 5 & 160 & $\geq 18$ & $\begin{array}{l}\text { Group 1: Kangbingdu granules }+\mathrm{CT} \\
\text { Group 2: CT }\end{array}$ & $\begin{array}{l}\text { Primary outcomes: } 1 \\
\text { Secondary outcomes: } 0\end{array}$ \\
\hline $\begin{array}{l}\text { Zhang } \\
{[38]}\end{array}$ & $\mathrm{RCT}$ & COVID-19 & Beijing, China & 1 & 60 & $18-80$ & $\begin{array}{l}\text { Group 1: CT } \\
\text { Group 2: TCM syndrome differentiation } \\
\text { treatment + CT }\end{array}$ & $\begin{array}{l}\text { Primary outcomes: } 4 \\
\text { Secondary outcomes: } 0\end{array}$ \\
\hline Wang L [39] & RCT & COVID-19 & $\begin{array}{l}\text { Shanghai, } \\
\text { China }\end{array}$ & 1 & 120 & $18-81$ & $\begin{array}{l}\text { Group 1: CT } \\
\text { Group 2: TCM + CT }\end{array}$ & $\begin{array}{l}\text { Primary outcomes: } 1 \\
\text { Secondary outcomes: } 4\end{array}$ \\
\hline Lu H [40] & RCT & $\begin{array}{l}\text { Mild and } \\
\text { common type } \\
\text { of } \\
\text { COVID-19 }\end{array}$ & $\begin{array}{l}\text { Shanghai, } \\
\text { China }\end{array}$ & 1 & 72 & $18-75$ & $\begin{array}{l}\text { Group 1: Tanreqing Capsules + CT } \\
\text { Group 2: CT }\end{array}$ & $\begin{array}{l}\text { Primary outcomes: } 2 \\
\text { Secondary outcomes: } 5\end{array}$ \\
\hline Zhai X [41] & Non-RCT & COVID-19 & $\begin{array}{l}\text { Shanghai, } \\
\text { China }\end{array}$ & 1 & 30 & $0-18$ & $\begin{array}{l}\text { Group 1: CT } \\
\text { Group 2: } \mathrm{TCM}+\mathrm{CT}\end{array}$ & $\begin{array}{l}\text { Primary outcomes: } 4 \\
\text { Secondary outcomes: } 1\end{array}$ \\
\hline
\end{tabular}

CT: conventional therapy (including any western routine treatment); OS: observational study; RCT: randomized controlled trial; TCM: traditional Chinese medicine 
Table 3 The characteristics of included protocols for western medicine clinical trials

\begin{tabular}{|c|c|c|c|c|c|c|c|c|c|c|}
\hline Study I & & $\begin{array}{l}\text { Study } \\
\text { type }\end{array}$ & Type of disease & $\begin{array}{l}\text { Primary } \\
\text { sponsor }\end{array}$ & $\begin{array}{l}\text { Number } \\
\text { of settings }\end{array}$ & $\begin{array}{l}\text { Sample } \\
\text { size }\end{array}$ & $\begin{array}{l}\text { Population' } \\
\text { age (years) }\end{array}$ & $\begin{array}{l}\text { Course of } \\
\text { treatment }\end{array}$ & Intervention & Number of outcomes \\
\hline $\begin{array}{l}\text { Huang } \\
{[5]}\end{array}$ & $\mathrm{C}$ & RCT & $\begin{array}{l}\text { Unexplained } \\
\text { viral pneumonia } \\
\text { or COVID-19 }\end{array}$ & $\begin{array}{l}\text { Hubei } \\
\text { province, } \\
\text { China }\end{array}$ & 1 & 160 & $\geq 18$ & & $\begin{array}{l}\text { Group: Lopinavir-ritonavir tablets }+ \\
\text { interferon- } \alpha 2 \mathrm{~b} \\
\text { Group 2: CT }\end{array}$ & $\begin{array}{l}\text { Primary outcomes: } 2 \\
\text { Secondary outcomes: } 9\end{array}$ \\
\hline $\begin{array}{l}\text { Chen } \\
{[42]}\end{array}$ & $\mathrm{Y}$ & $\mathrm{RCT}$ & COVID-19 & $\begin{array}{l}\text { Chongqing, } \\
\text { China }\end{array}$ & 1 & 40 & $\geq 18$ & & $\begin{array}{l}\text { Group 1: Lopinavir-ritonavir tablets }+ \\
\text { Aerosolized interferon- } \alpha \\
\text { Methylprednisolone } \\
\text { Group 2: Lopinavir-ritonavir tablets } \\
\text { Aerosolized interferon- } \alpha\end{array}$ & $\begin{array}{l}\text { Primary outcomes: } 3 \\
\text { Secondary outcomes: } 3\end{array}$ \\
\hline $\begin{array}{l}\text { Zhao } \\
{[43]}\end{array}$ & $\mathrm{D}$ & RCT & COVID-19 & $\begin{array}{l}\text { Liaoning } \\
\text { Province, } \\
\text { China }\end{array}$ & 2 & 45 & $\geq 18$ & Unclear & $\begin{array}{l}\text { Group 1: Critical Treatment in Critical } \\
\text { Period + Ankylosaurus } \\
\text { Group2: Critical Treatment in Critical } \\
\text { Period + Ankylosaurus+M1 suppression } \\
\text { therapy } \\
\text { Group 3: Critical Treatment in Critical } \\
\text { Period }\end{array}$ & $\begin{array}{l}\text { Primary outcomes: } 2 \\
\text { Secondary outcomes: } 0\end{array}$ \\
\hline $\begin{array}{l}\text { Jiang } \\
{[44]}\end{array}$ & $\mathrm{H}$ & $\begin{array}{l}\text { Non-RC } \\
\mathrm{T}\end{array}$ & COVID-19 & $\begin{array}{l}\text { Sichuan } \\
\text { Province, } \\
\text { China }\end{array}$ & 2 & 120 & $18-80$ & Unclear & $\begin{array}{l}\text { Group 1: Lopinavir/litonavir (LPV/r)+ } \\
\text { emtritabine (FTC)/ Tenofovir alafenamide } \\
\text { Fumarate tablets (TAF) } \\
\text { Group 2: LPV/r }\end{array}$ & $\begin{array}{l}\text { Primary outcomes: } 1 \\
\text { Secondary outcomes: } 3\end{array}$ \\
\hline $\begin{array}{l}\text { Jiang } \\
{[45]}\end{array}$ & S & $\begin{array}{l}\text { Non-RC } \\
\mathrm{T}\end{array}$ & COVID-19 & $\begin{array}{l}\text { Guangdong } \\
\text { Province, } \\
\text { China }\end{array}$ & 1 & 20 & $\geq 18$ & Unclear & $\begin{array}{l}\text { Group 1: chloroquine } \\
\text { Group 2:CT }\end{array}$ & $\begin{array}{ll}\text { Primary outcomes: } & 2 \\
\text { Secondary outcomes: } & 5 \\
\text { Other outcomes: } 4 & \end{array}$ \\
\hline $\begin{array}{l}\text { Wang } \\
{[46]}\end{array}$ & $X$ & $\mathrm{RCT}$ & COVID-19 & $\begin{array}{l}\text { Hubei } \\
\text { province, } \\
\text { China }\end{array}$ & 1 & 100 & $18-65$ & 14 days & $\begin{array}{l}\text { Group 1: Darunavir/cobicistat }+ \text { thymosin } \\
\alpha 1+\mathrm{CT} \\
\text { Group 2: } \mathrm{LPV} / \mathrm{r}+\text { hymosin } \alpha 1+\mathrm{CT} \\
\text { Group 3: hymosin } \alpha 1\end{array}$ & $\begin{array}{l}\text { Primary outcomes: } 1 \\
\text { Secondary outcomes: } 8\end{array}$ \\
\hline $\begin{array}{l}\text { Zhao } \\
{[47]}\end{array}$ & $\mathrm{J}$ & RCT & $\begin{array}{l}\text { Mild } \\
\text { COVID-19 }\end{array}$ & $\begin{array}{l}\text { Hubei } \\
\text { province, } \\
\text { China }\end{array}$ & 1 & 328 & $\geq 18$ & Unclear & $\begin{array}{l}\text { Group 1: Lopinavir-Ritonavir + CT } \\
\text { Group 2: CT }\end{array}$ & $\begin{array}{l}\text { Primary outcomes: } 1 \\
\text { Secondary outcomes: } 8\end{array}$ \\
\hline $\begin{array}{l}\text { Gong } \\
{[48]}\end{array}$ & G & $\mathrm{RCT}$ & $\begin{array}{l}\text { Mild and severe } \\
\text { COVID-19 }\end{array}$ & $\begin{array}{l}\text { Hunan } \\
\text { province, } \\
\text { China }\end{array}$ & 6 & 240 & $18-70$ & $7-14$ days & $\begin{array}{l}\text { Group 1: Novaferon Atomization inhalation } \\
+ \text { CT } \\
\text { Group 2: lopinavir / ritonavir tablets } \\
\text { (Kaletra) + CT } \\
\text { Group 3: Novafron + Kaletra + CT } \\
\text { Group 4: CT }\end{array}$ & $\begin{array}{l}\text { Primary outcomes: } 1 \\
\text { Secondary outcomes: } 3\end{array}$ \\
\hline
\end{tabular}




\begin{tabular}{|c|c|c|c|c|c|c|c|c|c|}
\hline Study ID & $\begin{array}{l}\text { Study } \\
\text { type }\end{array}$ & Type of disease & $\begin{array}{l}\text { Primary } \\
\text { sponsor }\end{array}$ & $\begin{array}{l}\text { Number } \\
\text { of settings }\end{array}$ & $\begin{array}{l}\text { Sample } \\
\text { size }\end{array}$ & $\begin{array}{l}\text { Population' } \\
\text { age (years) }\end{array}$ & $\begin{array}{l}\text { Course of } \\
\text { treatment }\end{array}$ & Intervention & Number of outcomes \\
\hline $\begin{array}{l}\text { Qiu } \\
{[49]}\end{array}$ & RCT & COVID-19 & $\begin{array}{l}\text { Zhejiang } \\
\text { Province, } \\
\text { China }\end{array}$ & 1 & 30 & $18-75$ & $\leq 14$ days & $\begin{array}{l}\text { Group 1: Baloxavir Marboxil } \\
\text { Group 2: Favipiravir } \\
\text { Group 3: Lopinavir-Ritonavir }\end{array}$ & $\begin{array}{l}\text { Primary outcomes: } 2 \\
\text { Secondary outcomes: } 8\end{array}$ \\
\hline $\begin{array}{l}\text { Zhang Z } \\
{[50]}\end{array}$ & RCT & COVID-19 & $\begin{array}{l}\text { Hubei } \\
\text { province, } \\
\text { China }\end{array}$ & 1 & 300 & $30-65$ & Unclear & $\begin{array}{l}\text { Group 1: Low dose of Hydroxychloroquine } \\
\text { Group 2: High dose of Hydroxychloroquine } \\
\text { Group 3: Placebo }\end{array}$ & $\begin{array}{l}\text { Primary outcomes: } 1 \\
\text { Secondary outcomes: } 1\end{array}$ \\
\hline Lv Q [51] & RCT & COVID-19 & $\begin{array}{l}\text { Zhejiang } \\
\text { Province, } \\
\text { China }\end{array}$ & 1 & 600 & $18-65$ & Unclear & $\begin{array}{l}\text { Group 1: Arbidol Tablets } \\
\text { Group 2: Novaferon injection, atomized } \\
\text { inhalation + Arbidol Tablets } \\
\text { Group 3: Lopinavir/litonavir } \\
\text { Group 4: Arbidol Tablets } \\
\text { Group 5: Novaferon injection, atomized } \\
\text { inhalation + Lopinavir/litonavir } \\
\text { Group 6: Novaferon injection, atomized } \\
\text { inhalation + Arbidol Tablets }\end{array}$ & $\begin{array}{l}\text { Primary outcomes: } 1 \\
\text { Secondary outcomes: } 0\end{array}$ \\
\hline $\begin{array}{l}\text { Zhou } \\
{[52]}\end{array}$ & RCT & $\begin{array}{l}\text { Severe type of } \\
\text { COVID-19 }\end{array}$ & $\begin{array}{l}\text { Hubei } \\
\text { province, } \\
\text { China }\end{array}$ & 1 & 70 & $18-75$ & Unclear & $\begin{array}{l}\text { Group 1: Ruxolitinib combined with } \\
\text { mesenchymal stem cell } \\
\text { Group 2: CT }\end{array}$ & $\begin{array}{l}\text { Primary outcomes: } 1 \\
\text { Secondary outcomes: } 0\end{array}$ \\
\hline $\begin{array}{l}\text { Qiu } \\
{[53]}\end{array}$ & RCT & $\begin{array}{l}\text { COVID-19 } \\
\text { (Severe and } \\
\text { critical types are } \\
\text { excluded) }\end{array}$ & $\begin{array}{l}\text { Zhejiang } \\
\text { Province, } \\
\text { China }\end{array}$ & 5 & 160 & $18-75$ & Unclear & $\begin{array}{l}\text { Group 1: ASC09/Ritonavir + CT } \\
\text { Group 2: Lopinavir/Ritonavir + CT }\end{array}$ & $\begin{array}{l}\text { Primary outcomes: } 1 \\
\text { Secondary outcomes: } 9\end{array}$ \\
\hline $\begin{array}{l}\text { Liu } \\
{[54]}\end{array}$ & $\begin{array}{l}\text { Non-RC } \\
\mathrm{T}\end{array}$ & COVID-19 & $\begin{array}{l}\text { Shenzhen } \\
\text { Province, } \\
\text { China }\end{array}$ & 1 & 90 & $16-75$ & Unclear & $\begin{array}{l}\text { Group 1: alpha-Interferon atomization } \\
\text { Group 2: Lopinavir and Ritonavir }+ \\
\text { alpha-Interferon atomization } \\
\text { Group 3: Favipiravir + alpha-Interferon } \\
\text { atomization }\end{array}$ & $\begin{array}{l}\text { Primary outcomes: } 5 \\
\text { Secondary outcomes: } 0\end{array}$ \\
\hline $\begin{array}{l}\text { Chen } \\
{[55]}\end{array}$ & $\mathrm{RCT}$ & $\begin{array}{l}\text { Mild type of } \\
\text { COVID-19 }\end{array}$ & $\begin{array}{l}\text { Chongqing, } \\
\text { China }\end{array}$ & 1 & 108 & $18-65$ & Unclear & $\begin{array}{l}\text { Group 1: Ribavirin + Interferon alpha-1b } \\
\text { Group 2: lopinavir / ritonavir + interferon } \\
\text { alpha-1b } \\
\text { Group 3: Ribavirin + LPV/r+Interferon } \\
\text { alpha-1b }\end{array}$ & $\begin{array}{l}\text { Primary outcomes: } 1 \\
\text { Secondary outcomes: } 5\end{array}$ \\
\hline
\end{tabular}




\begin{tabular}{|c|c|c|c|c|c|c|c|c|c|}
\hline Study ID & $\begin{array}{l}\text { Study } \\
\text { type }\end{array}$ & Type of disease & $\begin{array}{l}\text { Primary } \\
\text { sponsor }\end{array}$ & $\begin{array}{l}\text { Number } \\
\text { of settings }\end{array}$ & $\begin{array}{l}\text { Sample } \\
\text { size }\end{array}$ & $\begin{array}{l}\text { Population' } \\
\text { age (years) }\end{array}$ & $\begin{array}{l}\text { Course of } \\
\text { treatment }\end{array}$ & Intervention & Number of outcomes \\
\hline $\begin{array}{l}\text { Shan } \\
{[56]}\end{array}$ & OS & COVID-19 & $\begin{array}{l}\text { Guangdong } \\
\text { Province, } \\
\text { China }\end{array}$ & 2 & 205 & $\geq 18$ & Unclear & $\begin{array}{l}\text { Group 1: mild-moderate chloroquine } \\
\text { Group 2: mild-moderate Lopinavir/ } \\
\text { ritonavir } \\
\text { Group 3: mild-moderate combination group } \\
\text { (chloroquine phosphate + } \\
\text { Lopinavir/ritonavir) } \\
\text { Group 4: severe-chloroquine } \\
\text { 5: severe- Lopinavir/ritonavir }\end{array}$ & $\begin{array}{l}\text { Primary outcomes: } 1 \\
\text { Secondary outcomes: } 4\end{array}$ \\
\hline $\begin{array}{l}\text { Pei } \\
{[57]}\end{array}$ & RCT & $\begin{array}{l}\text { Severe and } \\
\text { critical type of } \\
\text { COVID-19 }\end{array}$ & $\begin{array}{l}\text { Hubei } \\
\text { province, } \\
\text { China }\end{array}$ & 1 & 30 & $\geq 18$ & Unclear & $\begin{array}{l}\text { Group 1: CT } \\
\text { Group 2: umbilical cord blood } \\
\text { mononuclear cells }+ \text { CT }\end{array}$ & $\begin{array}{l}\text { Primary outcomes: } 1 \\
\text { Secondary outcomes: } 8\end{array}$ \\
\hline $\begin{array}{l}\text { Pei } \\
{[58]}\end{array}$ & $\mathrm{RCT}$ & $\begin{array}{l}\text { Severe and } \\
\text { critical type of } \\
\text { COVID-19 }\end{array}$ & $\begin{array}{l}\text { Hubei } \\
\text { province, } \\
\text { China }\end{array}$ & 1 & 30 & $\geq 18$ & Unclear & $\begin{array}{l}\text { Group 1: CT } \\
\text { Group 2: umbilical cord mesenchymal stem } \\
\text { cell conditioned medium }+\mathrm{CT}\end{array}$ & $\begin{array}{l}\text { Primary outcomes: } 1 \\
\text { Secondary outcomes: } 8\end{array}$ \\
\hline $\begin{array}{l}\text { Qiu } \\
\text { [59] }\end{array}$ & RCT & COVID-19 & $\begin{array}{l}\text { Zhejiang } \\
\text { Province, } \\
\text { China }\end{array}$ & 1 & 30 & $18-75$ & Unclear & $\begin{array}{l}\text { Group 1: current antiviral treatment }+ \\
\text { Baloxavir Marboxil tablets } \\
\text { Group 2: current antiviral treatment }+ \\
\text { fabiravir tablets } \\
\text { Group 3: current antiviral treatment }\end{array}$ & $\begin{array}{l}\text { Primary outcomes: } 2 \\
\text { Secondary outcomes: } 6\end{array}$ \\
\hline $\begin{array}{l}\mathrm{Hu} \\
{[60]}\end{array}$ & OS & $\begin{array}{l}\text { Common or } \\
\text { severe type of } \\
\text { COVID-19 }\end{array}$ & $\begin{array}{l}\text { Hubei } \\
\text { province, } \\
\text { China }\end{array}$ & 1 & 40 & $\geq 18$ & Unclear & Group 1: vMIP atomized inhalation $+\mathrm{CT}$ & $\begin{array}{l}\text { Primary outcomes: } 2 \\
\text { Secondary outcomes: } 2\end{array}$ \\
\hline $\begin{array}{ll}\text { Liu } & \text { L } \\
{[61]} & \end{array}$ & $\mathrm{RCT}$ & COVID-19 & $\begin{array}{l}\text { Sichuan } \\
\text { Province, } \\
\text { China }\end{array}$ & 8 & 60 & $18-75$ & Unclear & $\begin{array}{l}\text { Group 1: nebulization of novel gene } \\
\text { recombinant super compound interferon } \\
\text { Group 2: nebulization of alpha-interferon }\end{array}$ & $\begin{array}{l}\text { Primary outcomes: } 9 \\
\text { Secondary outcomes: } 6\end{array}$ \\
\hline Li L [62] & RCT & COVID-19 & $\begin{array}{l}\text { Zhejiang } \\
\text { Province, } \\
\text { China }\end{array}$ & 1 & 63 & $1-99$ & Unclear & $\begin{array}{l}\text { Group 1a: CT }+ \text { Intravenous infusion of } \\
\text { Human Menstrual Blood-derived Stem } \\
\text { Cells preparations } \\
\text { Group 1b: CT } \\
\text { Group 2a: Artificial liver therapy }+ \text { CT } \\
\text { Group 2b: Artificial liver therapy + } \\
\text { Intravenous infusion of Human Menstrual } \\
\text { Blood-derived Stem Cells preparations + }\end{array}$ & $\begin{array}{l}\text { Primary outcomes: } 1 \\
\text { Secondary outcomes: } 8\end{array}$ \\
\hline
\end{tabular}




\begin{tabular}{|c|c|c|c|c|c|c|c|c|c|}
\hline Study ID & $\begin{array}{l}\text { Study } \\
\text { type }\end{array}$ & Type of disease & $\begin{array}{l}\text { Primary } \\
\text { sponsor }\end{array}$ & $\begin{array}{l}\text { Number } \\
\text { of settings }\end{array}$ & $\begin{array}{l}\text { Sample } \\
\text { size }\end{array}$ & $\begin{array}{l}\text { Population' } \\
\text { age (years) }\end{array}$ & $\begin{array}{l}\text { Course of } \\
\text { treatment }\end{array}$ & Intervention & Number of outcomes \\
\hline & & & & & & & & $\mathrm{CT}$ & \\
\hline $\begin{array}{l}\mathrm{Wu} \\
{[63]}\end{array}$ & RCT & $\begin{array}{l}\text { critical } \\
\text { COVID-19 }\end{array}$ & $\begin{array}{l}\text { Guangdong } \\
\text { Province, } \\
\text { China }\end{array}$ & 1 & 60 & $18-80$ & Unclear & $\begin{array}{l}\text { Group 1: high-fow therapy by nasal } \\
\text { cannulae (HFNC) } \\
\text { Group 2: bag- valve mask oxygenation } \\
\text { (SMO) }\end{array}$ & $\begin{array}{l}\text { Primary outcomes: } 1 \\
\text { Secondary outcomes: } 6\end{array}$ \\
\hline $\begin{array}{ll}\mathrm{Du} & \mathrm{R} \\
{[64]} & \end{array}$ & RCT & COVID-19 & $\begin{array}{l}\text { Hubei } \\
\text { province, } \\
\text { China }\end{array}$ & 1 & 100 & $\geq 18$ & Unclear & $\begin{array}{l}\text { Group 1: CT } \\
\text { Group 2: methylprednisolone }+ \text { CT }\end{array}$ & $\begin{array}{l}\text { Primary outcomes: } 5 \\
\text { Secondary outcomes: } 0\end{array}$ \\
\hline Qu J [65] & RCT & $\begin{array}{l}\text { COVID-19 } \\
\text { (Mild/common } \\
\text { type) }\end{array}$ & $\begin{array}{l}\text { Shanghai, } \\
\text { China }\end{array}$ & 1 & 380 & $\geq 18$ & Unclear & $\begin{array}{l}\text { Group 1: Arbidol tablets + CT } \\
\text { Group 2: CT }\end{array}$ & $\begin{array}{l}\text { Primary outcomes: } 1 \\
\text { Secondary outcomes: } 8\end{array}$ \\
\hline $\begin{array}{l}\text { Not } \\
\text { Provided } \\
{[66]}\end{array}$ & RCT & COVID-19 & $\begin{array}{l}\text { Beijing, } \\
\text { China }\end{array}$ & 4 & 80 & $\geq 18$ & 5 days & $\begin{array}{l}\text { Group 1: standard care } \\
\text { Group 2: standard care }+ \\
\text { Methylprednisolone }\end{array}$ & $\begin{array}{l}\text { Primary outcomes: } 2 \\
\text { Secondary outcomes: } 8\end{array}$ \\
\hline Lu H [67] & RCT & COVID-19 & $\begin{array}{l}\text { Shanghai, } \\
\text { China }\end{array}$ & 1 & 30 & $\begin{array}{l}\text { Child, Adult, } \\
\text { Older Adult }\end{array}$ & Unclear & $\begin{array}{l}\text { Group 1: Darunavir + Cobicistat }+ \text { CT } \\
\text { Group 2: CT }\end{array}$ & $\begin{array}{l}\text { Primary outcomes: } 1 \\
\text { Secondary outcomes: } 5\end{array}$ \\
\hline $\begin{array}{ll}\text { Qin } & N \\
{[68]} & \end{array}$ & RCT & COVID-19 & $\begin{array}{l}\text { Hubei } \\
\text { province, } \\
\text { China }\end{array}$ & 1 & 100 & $\geq 18$ & 2 weeks & $\begin{array}{l}\text { Group 1: Abidol hydrochloride } \\
\text { Group 2: Abidol Hydrochloride + Interferon } \\
\text { atomization }\end{array}$ & $\begin{array}{l}\text { Primary outcomes: } 2 \\
\text { Secondary outcomes: } 5\end{array}$ \\
\hline $\begin{array}{ll}\text { Qin } & N \\
\text { [69] }\end{array}$ & RCT & COVID-19 & $\begin{array}{l}\text { Hubei } \\
\text { province, } \\
\text { China }\end{array}$ & 1 & 400 & $\geq 18$ & 2 weeks & $\begin{array}{l}\text { Group 1: Symptomatic supportive treatment } \\
\text { Group 2: Abidol hydrochloride was added } \\
\text { on the basis of group } 1 \text {. } \\
\text { Group 3: Oseltamivir was added on the } \\
\text { basis of group 1. } \\
\text { Group 4: Lopinavir/ritonavir was added on } \\
\text { the basis of group } 1 \text {. }\end{array}$ & $\begin{array}{l}\text { Primary outcomes: } 2 \\
\text { Secondary outcomes: } 5\end{array}$ \\
\hline
\end{tabular}




\begin{tabular}{|c|c|c|c|c|c|c|c|c|c|}
\hline Study ID & $\begin{array}{l}\text { Study } \\
\text { type }\end{array}$ & Type of disease & $\begin{array}{l}\text { Primary } \\
\text { sponsor }\end{array}$ & $\begin{array}{l}\text { Number } \\
\text { of settings }\end{array}$ & $\begin{array}{l}\text { Sample } \\
\text { size }\end{array}$ & $\begin{array}{l}\text { Population' } \\
\text { age (years) }\end{array}$ & $\begin{array}{l}\text { Course of } \\
\text { treatment }\end{array}$ & Intervention & Number of outcomes \\
\hline $\begin{array}{ll}\text { Cao } & \text { B } \\
{[70]} & \end{array}$ & RCT & COVID-19 & $\begin{array}{l}\text { Beijing, } \\
\text { China }\end{array}$ & 2 & 308 & $\geq 18$ & 9 days & $\begin{array}{l}\text { Group 1: Remdesivir group active } \\
\text { remdesivir } \\
\text { Group 2: Control group } \\
\text { Placebos matched remdesivir }\end{array}$ & $\begin{array}{l}\text { Primary outcomes: } 1 \\
\text { Secondary outcomes: } 10\end{array}$ \\
\hline $\begin{array}{ll}\mathrm{Cao} & \mathrm{B} \\
{[71]} & \end{array}$ & RCT & $\begin{array}{l}\text { Severe } \\
\text { COVID-19 }\end{array}$ & $\begin{array}{l}\text { Beijing, } \\
\text { China }\end{array}$ & 1 & 452 & $\geq 18$ & 9 days & $\begin{array}{l}\text { Group 1: Remdesivir } \\
\text { Group 2: Remdesivir Placebo }\end{array}$ & $\begin{array}{l}\text { Primary outcomes: } 1 \\
\text { Secondary outcomes: } 10\end{array}$ \\
\hline Qu J [72] & $\mathrm{RCT}$ & $\begin{array}{l}\text { Mild or } \\
\text { common type of } \\
\text { COVID-19 }\end{array}$ & $\begin{array}{l}\text { Shanghai, } \\
\text { China }\end{array}$ & 1 & 380 & $18-75$ & $\begin{array}{l}14-20 \\
\text { days }\end{array}$ & $\begin{array}{l}\text { Group 1: Arbidol tablets + basic treatment } \\
\text { Group 2: basic treatment }\end{array}$ & $\begin{array}{l}\text { Primary outcomes: } 1 \\
\text { Secondary outcomes: } 8\end{array}$ \\
\hline $\begin{array}{ll}\text { Qin } & N \\
{[73]} & \end{array}$ & RCT & $\begin{array}{l}\text { COVID-19 } \\
\text { (without severe } \\
\text { type) }\end{array}$ & $\begin{array}{l}\text { Hubei } \\
\text { province, } \\
\text { China }\end{array}$ & 1 & 60 & $18-55$ & 14 days & $\begin{array}{l}\text { Group 1: ASC09F+Oseltamivir } \\
\text { Group 2: Ritonavir+Oseltamivir } \\
\text { Group 3: Oseltamivir }\end{array}$ & $\begin{array}{l}\text { Primary outcomes: } 1 \\
\text { Secondary outcomes: } 9\end{array}$ \\
\hline Li T [74] & $\mathrm{RCT}$ & $\begin{array}{l}\text { Severe type of } \\
\text { COVID-19 }\end{array}$ & $\begin{array}{l}\text { Beijing, } \\
\text { China }\end{array}$ & 2 & 80 & $\geq 18$ & Unclear & $\begin{array}{l}\text { Group 1: IVIG therapy+ standard care } \\
\text { Group 2: Standard care }\end{array}$ & $\begin{array}{l}\text { Primary outcomes: } 3 \\
\text { Secondary outcomes: } 8\end{array}$ \\
\hline Lu H [75] & $\mathrm{RCT}$ & COVID-19 & $\begin{array}{l}\text { Shanghai, } \\
\text { China }\end{array}$ & 1 & 30 & $\geq 18$ & 5 days & $\begin{array}{l}\text { Group 1: Hydroxychloroquine + CT } \\
\text { Group 2: CT }\end{array}$ & $\begin{array}{l}\text { Primary outcomes: } 4 \\
\text { Secondary outcomes: } 2\end{array}$ \\
\hline $\begin{array}{l}\text { Zhang Z } \\
{[76]}\end{array}$ & $\mathrm{RCT}$ & COVID-19 & $\begin{array}{l}\text { Beijing, } \\
\text { China }\end{array}$ & 1 & 200 & $16-99$ & Unclear & $\begin{array}{l}\text { Group 1: hydroxycholoroquine Group 2: } \\
\text { CT }\end{array}$ & $\begin{array}{l}\text { Primary outcomes: } 7 \\
\text { Secondary outcomes: } 4 \\
\text { Other outcomes: } 1\end{array}$ \\
\hline Xia J [77] & $\mathrm{RCT}$ & $\begin{array}{l}\text { Mild/generalCO } \\
\text { VID-19 }\end{array}$ & $\begin{array}{l}\text { Guangdong } \\
\text { Province, } \\
\text { China }\end{array}$ & 1 & 112 & $\geq 18$ & Unclear & $\begin{array}{l}\text { Group 1: Chloroquine Phosphate } \\
\text { Group 2: Lopinavir / Ritonavir }\end{array}$ & $\begin{array}{l}\text { Primary outcomes: } 10 \\
\text { Secondary outcomes: } 2 \\
\text { Other outcomes: } 1\end{array}$ \\
\hline $\begin{array}{ll}\text { Ning } & \text { Q } \\
{[78]} & \end{array}$ & RCT & OVID-19 & $\begin{array}{l}\text { Hubei } \\
\text { province, } \\
\text { China }\end{array}$ & 1 & 90 & $18-70$ & Unclear & $\begin{array}{l}\text { General patients group 1: CT } \\
\text { General patients group 2: Sodium Aescinate } \\
+\mathrm{CT} \\
\text { Severe patients control group 1: CT }+ \\
\text { hormonotherapy } \\
\text { Severe patients control group 2: CT } \\
\text { Severe patients experimental group: } \\
\text { Sodium Aescinate }+\mathrm{CT}\end{array}$ & $\begin{array}{l}\text { Primary outcomes: } 1 \\
\text { Secondary outcomes: } 4\end{array}$ \\
\hline
\end{tabular}




\begin{tabular}{|c|c|c|c|c|c|c|c|c|c|}
\hline Study ID & $\begin{array}{l}\text { Study } \\
\text { type }\end{array}$ & Type of disease & $\begin{array}{l}\text { Primary } \\
\text { sponsor }\end{array}$ & $\begin{array}{l}\text { Number } \\
\text { of settings }\end{array}$ & $\begin{array}{l}\text { Sample } \\
\text { size }\end{array}$ & $\begin{array}{l}\text { Population' } \\
\text { age (years) }\end{array}$ & $\begin{array}{l}\text { Course of } \\
\text { treatment }\end{array}$ & Intervention & Number of outcomes \\
\hline $\begin{array}{ll}\text { Ning } & \text { Q } \\
{[79]} & \end{array}$ & RCT & $\begin{array}{l}\text { severe } \\
\text { OVID-19 }\end{array}$ & $\begin{array}{l}\text { Hubei } \\
\text { province, } \\
\text { China }\end{array}$ & 1 & 100 & $\geq 18$ & 7 days & $\begin{array}{l}\text { Group 1: Methylprednisolone }(<40 \mathrm{mg} / \mathrm{d}) \\
\text { Group 2: Methylprednisolone }(40 \sim 80 \mathrm{mg} / \mathrm{d})\end{array}$ & $\begin{array}{l}\text { Primary outcomes: } 2 \\
\text { Secondary outcomes: } 5\end{array}$ \\
\hline $\begin{array}{ll}\text { Qiu } & \text { Y } \\
{[80]} & \end{array}$ & RCT & OVID-19 & $\begin{array}{l}\text { Zhejiang } \\
\text { Province, } \\
\text { China }\end{array}$ & 2 & 160 & $18-75$ & 14 days & $\begin{array}{l}\text { Group 1: ASC09/ritonavir } \\
\text { Group 2: lopinavir/ritonavir }\end{array}$ & $\begin{array}{l}\text { Primary outcomes: } 1 \\
\text { Secondary outcomes: } 9\end{array}$ \\
\hline Li L [81] & $\mathrm{RCT}$ & OVID-19 & $\begin{array}{l}\text { Guangdong } \\
\text { Province, } \\
\text { China }\end{array}$ & 1 & 125 & 7-14 days & Unclear & $\begin{array}{l}\text { Group 1: CT + lopinavir/ritonavir } \\
\text { Group 2: CT + arbidol } \\
\text { Group 3: CT }\end{array}$ & $\begin{array}{l}\text { Primary outcomes: } 1 \\
\text { Secondary outcomes: } 4 \\
\text { Other outcomes: } 5\end{array}$ \\
\hline $\begin{array}{l}\text { Wang } F \\
{[82]}\end{array}$ & $\begin{array}{l}\text { Non-RC } \\
\mathrm{T}\end{array}$ & OVID-19 & $\begin{array}{l}\text { Beijing, } \\
\text { China }\end{array}$ & 7 & 40 & $18-65$ & Unclear & $\begin{array}{l}\text { Group 1: Mesenchymal Stem Cell + CT } \\
\text { Group 2: CT }\end{array}$ & $\begin{array}{l}\text { Primary outcomes: } 2 \\
\text { Secondary outcomes: } 7\end{array}$ \\
\hline $\begin{array}{l}\text { F Zhang } \\
\text { [83] }\end{array}$ & $\mathrm{RCT}$ & $\begin{array}{l}\text { Severe type of } \\
\text { COVID-19 }\end{array}$ & $\begin{array}{l}\text { Jiangsu } \\
\text { Province, } \\
\text { China }\end{array}$ & 1 & 40 & $14-70$ & Unclear & $\begin{array}{l}\text { Group 1: } \quad 5 \mathrm{u} \text { washed microbiota } \\
\text { suspension administered }+\mathrm{CT} \\
\text { Group 2: } 5 \mathrm{u} \text { placebo }+\mathrm{CT}\end{array}$ & $\begin{array}{ll}\text { Primary outcomes: } & 1 \\
\text { Secondary outcomes: } & 0\end{array}$ \\
\hline $\begin{array}{ll}\text { Peng } & Z \\
{[84]} & \end{array}$ & $\mathrm{RCT}$ & $\begin{array}{l}\text { Severe type of } \\
\text { COVID-19 }\end{array}$ & $\begin{array}{l}\text { Hubei } \\
\text { province, } \\
\text { China }\end{array}$ & 1 & 140 & $\geq 18$ & 7 days & $\begin{array}{l}\text { Group 1: Vit } \mathrm{C}+\text { water for injection } \\
\text { Group 2: Water for injection }\end{array}$ & $\begin{array}{l}\text { Primary outcomes: } 1 \\
\text { Secondary outcomes: } 8\end{array}$ \\
\hline $\begin{array}{l}\text { Cheng X } \\
\text { [85] }\end{array}$ & $\begin{array}{l}\text { Non-RC } \\
\mathrm{T}\end{array}$ & $\begin{array}{l}\text { Severe type of } \\
\text { COVID-19 }\end{array}$ & $\begin{array}{l}\text { Hubei } \\
\text { province, } \\
\text { China }\end{array}$ & 1 & 10 & $\geq 18$ & 3 days & $\begin{array}{l}\text { Group 1: Immunoglobulin of cured patients } \\
\text { Group 2: } \gamma \text {-Globulin }\end{array}$ & $\begin{array}{l}\text { Primary outcomes: } 1 \\
\text { Secondary outcomes: } 10\end{array}$ \\
\hline $\begin{array}{l}\text { Zhang Z } \\
{[86]}\end{array}$ & RCT & COVID-19 & $\begin{array}{l}\text { Hubei } \\
\text { province, } \\
\text { China }\end{array}$ & 1 & 238 & $18-60$ & Unclear & $\begin{array}{l}\text { Group 1: Xiyanping injection } \\
\text { Group 2: alpha-interferon }\end{array}$ & $\begin{array}{l}\text { Primary outcomes: } 7 \\
\text { Secondary outcomes: } 5\end{array}$ \\
\hline $\begin{array}{ll}\text { Liu } & Z \\
{[87]} & \end{array}$ & RCT & $\begin{array}{l}\text { Severe type of } \\
\text { COVID-19 }\end{array}$ & $\begin{array}{l}\text { Sichuan } \\
\text { Province, } \\
\text { China }\end{array}$ & 3 & 300 & $\geq 18$ & Unclear & $\begin{array}{l}\text { Group 1: convalescent plasma therapy + CT } \\
\text { Group 2: CT }\end{array}$ & $\begin{array}{l}\text { Primary outcomes: } 1 \\
\text { Secondary outcomes: } 13\end{array}$ \\
\hline $\begin{array}{l}\text { Kang } \mathrm{Y} \\
{[88]}\end{array}$ & OS & $\begin{array}{l}\text { Severe type of } \\
\text { COVID-19 }\end{array}$ & $\begin{array}{l}\text { Sichuan } \\
\text { Province, } \\
\text { China }\end{array}$ & 1 & 100 & Unclear & Unclear & NA & $\begin{array}{l}\text { Primary outcomes: } 6 \\
\text { Secondary outcomes: } 0\end{array}$ \\
\hline Hu P [89] & RCT & $\begin{array}{l}\text { Mild and } \\
\text { common type of } \\
\text { COVID-19 }\end{array}$ & $\begin{array}{l}\text { Chongqing, } \\
\text { China }\end{array}$ & 2 & 60 & $18-80$ & Unclear & $\begin{array}{l}\text { Group 1: Lopinavir / Ritonavir (Kaletra) + } \\
\text { IFN aerosol inhalation } \\
\text { Group 2: Abidol and IFN aerosol inhalation } \\
\text { Group 3: ASC09/ Ritonavir (ASC09F) + } \\
\text { IFN aerosol inhalation }\end{array}$ & $\begin{array}{l}\text { Primary outcomes: } 1 \\
\text { Secondary outcomes: } 8\end{array}$ \\
\hline
\end{tabular}




\begin{tabular}{|c|c|c|c|c|c|c|c|c|c|}
\hline Study ID & $\begin{array}{l}\text { Study } \\
\text { type }\end{array}$ & Type of disease & $\begin{array}{l}\text { Primary } \\
\text { sponsor }\end{array}$ & $\begin{array}{l}\text { Number } \\
\text { of settings }\end{array}$ & $\begin{array}{l}\text { Sample } \\
\text { size }\end{array}$ & $\begin{array}{l}\text { Population' } \\
\text { age (years) }\end{array}$ & $\begin{array}{l}\text { Course of } \\
\text { treatment }\end{array}$ & Intervention & Number of outcomes \\
\hline $\begin{array}{ll}\text { Mao } & \mathrm{H} \\
{[90]} & \end{array}$ & RCT & $\begin{array}{l}\text { mild and } \\
\text { moderate } \\
\text { COVID-19 }\end{array}$ & $\begin{array}{l}\text { Chongqing, } \\
\text { China }\end{array}$ & 2 & 240 & Unclear & Unclear & $\begin{array}{l}\text { Group 1: Hydroxychloroquin } \\
\text { Group 2: Lopinavir /Ritonavir }\end{array}$ & $\begin{array}{l}\text { Primary outcomes: } 1 \\
\text { Secondary outcomes: } 11\end{array}$ \\
\hline $\begin{array}{l}\text { Huang W } \\
\text { [91] }\end{array}$ & RCT & $\begin{array}{l}\text { Common type } \\
\text { of COVID-19 }\end{array}$ & $\begin{array}{l}\text { Chongqing, } \\
\text { China }\end{array}$ & 4 & 240 & $\geq 18$ & Unclear & $\begin{array}{l}\text { Group 1: Low-dose hydroxychloroquine + } \\
\text { CT } \\
\text { Group 2: Medium-dose } \\
\text { hydroxychloroquine }+ \text { CT } \\
\text { Group 3: High-dose hydroxychloroquine + } \\
\text { CT } \\
\text { Group 4: CT }\end{array}$ & $\begin{array}{l}\text { Primary outcomes: } 2 \\
\text { Secondary outcomes: } 5 \\
\text { Other outcomes: } 3\end{array}$ \\
\hline $\begin{array}{l}\text { Huang W } \\
\text { [92] }\end{array}$ & $\mathrm{RCT}$ & $\begin{array}{l}\text { Severe and } \\
\text { critical type of } \\
\text { COVID-19 }\end{array}$ & $\begin{array}{l}\text { Chongqing, } \\
\text { China }\end{array}$ & 4 & 60 & $\geq 18$ & Unclear & $\begin{array}{l}\text { Group 1: Hydroxychloroquine }+\mathrm{CT} \\
\text { Group 2: CT }\end{array}$ & $\begin{array}{l}\text { Primary outcomes: } 2 \\
\text { Secondary outcomes: } 7 \\
\text { Other outcomes: } 3\end{array}$ \\
\hline $\begin{array}{ll}\mathrm{Xu} & \mathrm{X} \\
{[93]} & \end{array}$ & $\mathrm{RCT}$ & $\begin{array}{l}\text { common type of } \\
\text { COVID-19 }\end{array}$ & $\begin{array}{l}\text { Anhui } \\
\text { Province, } \\
\text { China }\end{array}$ & 1 & 188 & $18-85$ & Unclear & $\begin{array}{l}\text { Group 1: CT } \\
\text { Group 2: tocilizumab + CT }\end{array}$ & $\begin{array}{l}\text { Primary outcomes: } 1 \\
\text { Secondary outcomes: } 3\end{array}$ \\
\hline Lin J [94] & RCT & $\begin{array}{l}\text { common type of } \\
\text { COVID-19 }\end{array}$ & $\begin{array}{l}\text { Hubei } \\
\text { province, } \\
\text { China }\end{array}$ & 1 & 60 & $18-75$ & Unclear & $\begin{array}{l}\text { Group 1: Diammonium Glycyrrhizinate } \\
\text { Enteric-coated Capsules }+ \text { Vitamin C } \\
\text { tablets+ CT } \\
\text { Group 2: clinical standard antiviral } \\
\text { treatment }\end{array}$ & $\begin{array}{l}\text { Primary outcomes: } 3 \\
\text { Secondary outcomes: } 4\end{array}$ \\
\hline $\begin{array}{l}\text { Huang X } \\
{[95]}\end{array}$ & RCT & COVID-19 & $\begin{array}{l}\text { Zhejiang } \\
\text { Province, } \\
\text { China }\end{array}$ & 2 & 40 & $\geq 18$ & Unclear & $\begin{array}{l}\text { Group 1: } \text { Polyinosinic-Polycytidylic } \\
\text { Injection } \\
\text { Group 2: }\end{array}$ & $\begin{array}{l}\text { Primary outcomes: } 1 \\
\text { Secondary outcomes: } 5\end{array}$ \\
\hline $\begin{array}{l}\mathrm{Wu} \quad \mathrm{W} \\
{[96]}\end{array}$ & $\begin{array}{l}\text { Cohort } \\
\text { study }\end{array}$ & $\begin{array}{l}\text { Severe } \\
\text { COVID-19 }\end{array}$ & $\begin{array}{l}\text { Hubei } \\
\text { province, } \\
\text { China }\end{array}$ & 3 & 100 & $\leq 75$ & Unclear & NA & $\begin{array}{l}\text { Primary outcomes: } 1 \\
\text { Secondary outcomes: } 3\end{array}$ \\
\hline Xia J [97] & $\mathrm{RCT}$ & $\begin{array}{l}\text { Severe } \\
\text { COVID-19 }\end{array}$ & $\begin{array}{l}\text { Hubei } \\
\text { province, } \\
\text { China }\end{array}$ & 1 & 120 & $\geq 18$ & Unclear & $\begin{array}{l}\text { Group 1: Thymosin } \\
\text { Group 2: Camrelizumab } \\
\text { Group 3: CT }\end{array}$ & $\begin{array}{l}\text { Primary outcomes: } 1 \\
\text { Secondary outcomes: } 0\end{array}$ \\
\hline $\begin{array}{l}\mathrm{Xu} \\
{[98]}\end{array}$ & RCT & $\begin{array}{l}\text { COVID-19 } \\
\text { (without severe } \\
\text { type) }\end{array}$ & $\begin{array}{l}\text { Guangdong } \\
\text { Province, } \\
\text { China }\end{array}$ & NA & 60 & $\geq 18$ & Unclear & $\begin{array}{l}\text { Group 1: Anti-aging Active Freeze-dried } \\
\text { Powder Granules + CT } \\
\text { Group 2: CT }\end{array}$ & $\begin{array}{l}\text { Primary outcomes: } 1 \\
\text { Secondary outcomes: } 6\end{array}$ \\
\hline
\end{tabular}




\begin{tabular}{|c|c|c|c|c|c|c|c|c|c|c|}
\hline \multicolumn{2}{|c|}{ Study ID } & \multirow{2}{*}{$\begin{array}{l}\text { Study } \\
\text { type }\end{array}$} & \multirow{2}{*}{$\begin{array}{l}\text { Type of disease } \\
\text { COVID-19 } \\
\text { (without severe } \\
\text { type) }\end{array}$} & \multirow{2}{*}{$\begin{array}{l}\text { Primary } \\
\text { sponsor } \\
\text { Guangdong } \\
\text { Province, } \\
\text { China }\end{array}$} & \multirow{2}{*}{$\begin{array}{l}\begin{array}{l}\text { Number } \\
\text { of settings }\end{array} \\
\text { NA }\end{array}$} & \multirow{2}{*}{$\begin{array}{l}\text { Sample } \\
\text { size }\end{array}$} & \multirow{2}{*}{$\begin{array}{l}\text { Population' } \\
\text { age (years) }\end{array}$} & \multirow{2}{*}{$\begin{array}{l}\begin{array}{l}\text { Course of } \\
\text { treatment }\end{array} \\
\text { Unclear }\end{array}$} & \multirow{2}{*}{$\begin{array}{l}\text { Intervention } \\
\text { Group 1: Intravenous infusion of Umbilical } \\
\text { Cord Blood Mononuclear Cells } \\
\text { preparations + CT } \\
\text { Group 2: CT }\end{array}$} & \multirow{2}{*}{$\begin{array}{l}\text { Number of outcomes } \\
\text { Primary outcomes: } 1 \\
\text { Secondary outcomes: } 6\end{array}$} \\
\hline $\begin{array}{l}\mathrm{Xu} \\
{[99]}\end{array}$ & $\mathrm{C}$ & & & & & & & & & \\
\hline $\begin{array}{l}\mathrm{Xu} \\
{[100]}\end{array}$ & $\mathrm{C}$ & RCT & $\begin{array}{l}\text { COVID-19 } \\
\text { (without severe } \\
\text { type) }\end{array}$ & $\begin{array}{l}\text { Guangdong } \\
\text { Province, } \\
\text { China }\end{array}$ & NA & 60 & $\geq 18$ & Unclear & $\begin{array}{l}\text { Group 1: Intravenous infusion of Cord } \\
\text { Blood Mesenchymal Stem Cells } \\
\text { preparations + CT } \\
\text { Group 2: CT }\end{array}$ & $\begin{array}{l}\text { Primary outcomes: } 1 \\
\text { Secondary outcomes: } 6\end{array}$ \\
\hline $\begin{array}{l}\mathrm{Xu} \\
{[101]}\end{array}$ & $\mathrm{C}$ & $\mathrm{RCT}$ & $\begin{array}{l}\text { COVID-19 } \\
\text { (without severe } \\
\text { type) }\end{array}$ & $\begin{array}{l}\text { Guangdong } \\
\text { Province, } \\
\text { China }\end{array}$ & NA & 60 & $\geq 18$ & Unclear & $\begin{array}{l}\text { Group 1: High-dose NK cells }+ \\
\text { mesenchymal stem cells } \\
\text { Group 2: Conventional dose NK cells }+ \\
\text { mesenchymal stem cells } \\
\text { Group 3: Preventive dose NK cells }+ \\
\text { mesenchymal stem cells }\end{array}$ & $\begin{array}{l}\text { Primary outcomes: } 1 \\
\text { Secondary outcomes: } 6\end{array}$ \\
\hline $\begin{array}{l}\mathrm{Xie} \\
{[102]}\end{array}$ & $\mathbf{J}$ & RCT & COVID-19 & $\begin{array}{l}\text { Chongqing, } \\
\text { China }\end{array}$ & 1 & 120 & $\geq 18$ & Unclear & $\begin{array}{l}\text { Group 1: Anti-PD-1 antibody } \\
\text { Group 2: Thymosin } \\
\text { Group 3: CT }\end{array}$ & $\begin{array}{l}\text { Primary outcomes: } 1 \\
\text { Secondary outcomes: } 6\end{array}$ \\
\hline $\begin{array}{l}\text { Peng } \\
{[103]}\end{array}$ & $\mathrm{Z}$ & OS & COVID-19 & $\begin{array}{l}\text { Hubei } \\
\text { Province, } \\
\text { China }\end{array}$ & 2 & 10 & $18-75$ & Unclear & $\begin{array}{l}\text { Group 1: Umbilical Cord-Derived } \\
\text { Mesenchymal Stem Cells }\end{array}$ & $\begin{array}{l}\text { Primary outcomes: } 1 \\
\text { Secondary outcomes: } 15\end{array}$ \\
\hline
\end{tabular}

CT: conventional therapy (including any western routine treatment); OS: observational study; RCT: randomized controlled trial 
medRxiv preprint doi: https://doi.org/10.1101/2020.03.04.20031401; this version posted March 8, 2020. The copyright holder for this preprint (which was not certified by peer review) is the author/funder, who has granted medRxiv a license to display the preprint in perpetuity.

All rights reserved. No reuse allowed without permission.

\section{The list of outcomes}

In protocols of TCM clinical trials, the number of primary outcomes are from $1(13 / 34,38.24 \%)$

to $13(1 / 34,2.94 \%)$, the number of secondary outcomes are from $1(7 / 34,20.59 \%)$ to $14(1 / 34$, $2.94 \%) .1(1 / 34,2.94 \%)$ protocol of clinical trial reports other outcomes. For individual clinical trial, the number of outcomes are from $1(2 / 34,5.88 \%)$ to $15(1 / 34,2.94 \%)$. The number of outcomes in protocols of TCM clinical trials is shown in Figure 2.

In protocols of western medicine clinical trials, the number of primary outcomes are from 1 (39/63, $61.90 \%)$ to $10(1 / 63,1.59 \%)$, the number of secondary outcomes are from $0(8 / 63,12.70 \%)$ to $15(1 / 63,1.59 \%) .5(5 / 63,7.94 \%)$ protocols of clinical trials reported other outcomes (the number of outcomes are from 1 to 5). For individual clinical trial, the number of outcomes are from 1 $(4 / 63,6.35 \%)$ to $16(1 / 63,1.59 \%)$. The number of outcomes in protocols of western medicine clinical trials is shown in Figure 3.

After merging and grouping outcomes, there are 76 different outcomes from 16 outcome domains in 34 protocols of TCM clinical trials (table 4). Almost half of outcomes are reported only once $(34 / 76,44.74 \%)$. The most frequently reported outcome is "time of SARS-CoV-2 RNA turns to negative", which is reported 16 times. Only $3(3 / 76,3.95 \%)$ outcomes are reported more than 10 times. Only $27(27 / 76,35.53 \%)$ outcomes are provided one or more outcome measurement instruments. Only 10 outcomes are provided one or more measurement time frame. The summary of outcome reporting for protocols of TCM clinical trials is shown in Figure 4.

In the 16 outcome domains of protocols of TCM clinical trials, 4 outcome domains (adverse events/effects, hepatobiliary outcomes, mortality/survival, psychiatric outcomes) consisted of only one outcome. These outcomes are reported between 1 and 9 times, and the median outcome reporting time was 6.5. Respiratory, thoracic and mediastinal outcomes have the largest number of outcomes, which includes 17 outcomes; chest imaging is reported more frequently than other outcomes. The number of outcomes in different outcome domains in protocols of TCM clinical trials is shown in Figure 5.

After merging and grouping, there are 126 different outcomes from 17 outcome domains in 63 protocols of western medicine clinical trials (table 5). Almost half of outcomes are reported only once $(62 / 126,49.21 \%)$. The most frequently reported outcome is "proportion of patients with negative SARS-CoV-2", which is reported 40 times. Only $11(11 / 126,8.73 \%)$ outcomes are reported more than 10 times. Only 27 outcomes are provided one or more outcome measurement instruments. Only $40(40 / 126,31.75 \%)$ outcomes are provided one or more measurement time frame. The summary of outcome reporting for protocols of TCM clinical trials is shown in Figure 6. 
In the 17 outcome domains of protocols of western medicine clinical trials, 5 outcome domains (adverse events/effects, delivery of care, economic, metabolism and nutrition outcomes, mortality/survival) consisted of only one outcome. These outcomes are reported between 1 and 36 times, and the median outcome reporting time is 1 . Respiratory, thoracic and mediastinal outcomes included the largest number of outcomes, which includes 31 outcomes; chest imaging is reported more frequently than other outcomes. The number of outcomes in different outcome domains in protocols of western medicine clinical trials is shown in Figure 7.

\section{DISCUSSION}

This review is the first to evaluate the outcome reporting of protocols of TCM and western medicine clinical trials for treating COVID-19. The results showed variations in the outcome reporting. For outcome measurement instruments/outcome definitions and outcome measurement time, there is also heterogeneity. However, many primary investigators did not provide outcome measurement instruments/outcome definitions or outcome measurement time. It is difficult to predict results of clinical trials now. But it is obvious that these problems may result in the exclusion of some studies from systematic reviews/meta-analyses due to the heterogeneity of outcomes or outcome measurements. It is a waste.

In this review, we find that there are more than 40 duplicated outcomes between protocols of TCM and western medicine clinical trials. No matter for clinical trials of TCM or western medicine, etiological test, chest imaging, respiratory symptoms, temperature, mortality/survival and adverse events are very important. These outcomes are relevant to the prognosis of disease and safety of therapy.

Because of no specific therapy can be used in the treatment of COVID-19, it is necessary and urgent to conduct clinical trials, no matter what the interventions are. We believe that it is important to develop a COS for clinical trials of TCM and western medicine for treating COVID-19, so that the efficacy of different interventions can be compared and merged in systematic review/meta-analysis. 
medRxiv preprint doi: https://doi.org/10.1101/2020.03.04.20031401; this version posted March 8, 2020. The copyright holder for this preprint (which was not certified by peer review) is the author/funder, who has granted medRxiv a license to display the preprint in perpetuity.

All rights reserved. No reuse allowed without permission.

Table 4 Outcomes from protocols of TCM clinical trials

\begin{tabular}{|l|l|l|l|}
\hline Outcome domain & Outcomes & $\begin{array}{l}\text { Number } \\
\text { of }\end{array}$ & Defination/ \\
& outcome \\
& outcomes & measurement & \\
\hline
\end{tabular}

Mortality/survival

\begin{tabular}{|l|l|l|l|}
\hline Mortality/survival & 8 & 0 & $\begin{array}{l}28 \text { days, } 84 \\
\text { days }\end{array}$ \\
\hline
\end{tabular}

\section{Physiological/clinical}

\begin{tabular}{|l|l|l|l|l|}
\hline $\begin{array}{l}\text { Blood and lymphatic } \\
\text { system outcomes }\end{array}$ & \multicolumn{1}{|c|}{ Not provided } \\
\hline & Blood routine test & 10 & 0 & Not provided \\
\hline Biochemical outcomes & 6 & 0 & Not provided \\
\hline CRP & 5 & 0 & Not provided \\
\hline Coagulation outcomes & 3 & 0 & Not provided \\
\hline Erythrocyte sedimentation & rate & 1 & 0 & Not provided \\
\hline High-sensitive CRP & 1 & 0 & & \\
\hline
\end{tabular}

Cardiac outcomes

\begin{tabular}{|l|l|l|l|}
\hline ECG & 1 & 1 & Not provided \\
\hline Heart function & 1 & 0 & Not provided \\
\hline Heart rate & 1 & 0 & Not provided \\
\hline Myocardial enzyme & 2 & 0 & Not provided \\
\hline $\begin{array}{l}\text { Myoglobin } \\
\text { Troponin }\end{array}$ & 1 & 0 & Not provided \\
\hline $\begin{array}{l}\text { Gastrointestinal } \\
\text { outcomes }\end{array}$ & 1 & 0 & Not provided \\
\hline $\begin{array}{l}\text { Clearance time of } \\
\text { gastrointestinal symptoms }\end{array}$ & 1 & 0 & Not provided \\
\hline $\begin{array}{l}\text { Remission of clinical symptoms: } \\
\text { gastrointestinal discomfort }\end{array}$ & 4 & 0 & Not provided \\
\hline
\end{tabular}


medRxiv preprint doi: https://doi.org/10.1101/2020.03.04.20031401; this version posted March 8, 2020. The copyright holder for this preprint (which was not certified by peer review) is the author/funder, who has granted medRxiv a license to display the preprint in perpetuity.

All rights reserved. No reuse allowed without permission.

\begin{tabular}{|l|l|l|l|}
\hline Outcome domain & Outcomes & $\begin{array}{l}\text { Number } \\
\text { of }\end{array}$ & $\begin{array}{l}\text { Defination/ } \\
\text { outcome }\end{array}$ \\
& outcomes & measurement & \\
\hline
\end{tabular}

General outcomes

\begin{tabular}{|l|l|l|l|}
\hline Blood pressure & 1 & 0 & Not provided \\
\hline Clearance time of fatigue & 1 & 0 & Not provided
\end{tabular}

\begin{tabular}{|l|l|l|}
\hline Clearance time of fever & 14 & 1.8 o'clock, 12 \\
o'clock, 16 \\
o'clock, and 20 \\
o'clock, \\
2.28 days
\end{tabular}

$\begin{array}{llll}\text { Clinical symptom score } & 1 & 0 & \text { Not provided }\end{array}$

\begin{tabular}{|l|l|l|l|}
\hline $\begin{array}{l}\text { Propotion of patients without } \\
\text { fatigue }\end{array}$ & 9 & 0 & Not provided \\
\hline $\begin{array}{l}\text { Proportion of patients without } \\
\text { fever }\end{array}$ & 3 & 0 & Not provided \\
$\begin{array}{l}\text { Remission of clinical symptoms: } \\
\text { fever }\end{array}$ & 4 & 0 & Not provided \\
\hline $\begin{array}{l}\text { Temperature } \\
\text { TCM syndromes }\end{array}$ & 3 & 0 & Not provided \\
\hline $\begin{array}{l}\text { The proportion of patients } \\
\text { without fever }\end{array}$ & 1 & 0 & Not provided \\
\hline $\begin{array}{l}\text { Time to remission/disappearance } \\
\text { of primary symptoms }\end{array}$ & 1 & 1 & Not provided \\
\hline \begin{tabular}{l} 
Net provided \\
\hline
\end{tabular}
\end{tabular}

Hepatobiliary outcomes

\begin{tabular}{|l|l|l|l|}
\hline Liver function & 5 & 0 & Not provided \\
\hline $\begin{array}{l}\text { Immune system } \\
\text { outcomes }\end{array}$ & 1 & 0 & Not provided \\
\hline HLA-DR & 1 & 0 & Not provided \\
\hline Immunoglobulin & 5 & 0 & Not provided \\
\hline $\begin{array}{l}\text { Procalcitonin } \\
\text { Rate of subjects receiving }\end{array}$ & 1 & 1 & 28 days \\
\hline
\end{tabular}


medRxiv preprint doi: https://doi.org/10.1101/2020.03.04.20031401; this version posted March 8, 2020. The copyright holder for this preprint (which was not certified by peer review) is the author/funder, who has granted medRxiv a license to display the preprint in perpetuity.

All rights reserved. No reuse allowed without permission.

\begin{tabular}{|l|l|l|l|}
\hline Outcome domain & Outcomes & $\begin{array}{l}\text { Number } \\
\text { of }\end{array}$ & $\begin{array}{l}\text { Defination/ } \\
\text { outcome }\end{array}$ \\
& outcomes & measurement & \\
\hline
\end{tabular}

Infection and

infestation outcomes

\begin{tabular}{|l|l|l|l|}
\hline $\begin{array}{l}\text { Incidence of antibiotic treatment } \\
\text { Proportion of patients with }\end{array}$ & 6 & 0 & $\begin{array}{l}\text { Not provided } \\
\text { at the end of } \\
\text { the treatment, } \\
\text { on the 28th day } \\
\text { of treatment }\end{array}$ \\
\hline $\begin{array}{l}\text { Time of SARS-CoV-2 RNA } \\
\text { turns to negative }\end{array}$ & 16 & 2 & Not provided \\
\hline
\end{tabular}

Renal and urinary

outcomes

\begin{tabular}{|l|l|l|l|}
\hline Urine routine & 2 & 0 & Not provided \\
\hline kidney function & 5 & 0 & Not provided \\
\hline
\end{tabular}

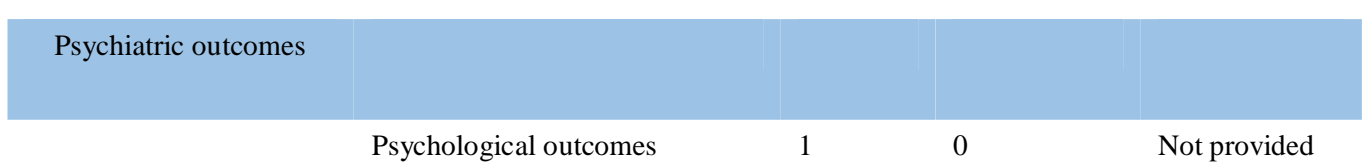

\begin{tabular}{|c|c|c|c|c|}
\hline \multicolumn{5}{|l|}{$\begin{array}{c}\text { Respiratory, thoracic } \\
\text { and mediastinal outcomes }\end{array}$} \\
\hline & $\mathrm{PaO} 2 / \mathrm{FiO} 2$ & 4 & 0 & Not provided \\
\hline & Chest imaging & 12 & 1 & Not provided \\
\hline & Blood oxygen saturation & 3 & 0 & Not provided \\
\hline & CURB-65 & 1 & 1 & Not provided \\
\hline & Clearance time of cough & 4 & 0 & Not provided \\
\hline & Pulmonary function & 6 & 0 & Not provided \\
\hline & $\begin{array}{l}\text { Duration of mechanical } \\
\text { ventilation }\end{array}$ & 3 & 1 & 28 days \\
\hline & $\begin{array}{l}\text { Improvement of lung HRCT } \\
\text { score }\end{array}$ & 2 & 1 & Not provided \\
\hline & Pneumonia severity index & 4 & 1 & Not provided \\
\hline & Proportion of patients without & 6 & 0 & Not provided \\
\hline
\end{tabular}


medRxiv preprint doi: https://doi.org/10.1101/2020.03.04.20031401; this version posted March 8, 2020. The copyright holder for this preprint (which was not certified by peer review) is the author/funder, who has granted medRxiv a license to display the preprint in perpetuity.

All rights reserved. No reuse allowed without permission.

\begin{tabular}{|c|c|c|c|c|}
\hline Outcome domain & Outcomes & $\begin{array}{l}\text { Number } \\
\text { of } \\
\text { outcomes }\end{array}$ & $\begin{array}{l}\text { Defination/ } \\
\text { outcome } \\
\text { measurement }\end{array}$ & Time point \\
\hline & cough & & & \\
\hline & $\begin{array}{l}\text { Proportion of patients without } \\
\text { sputum }\end{array}$ & 2 & 0 & Not provided \\
\hline & $\begin{array}{l}\text { Proportion of patients without } \\
\text { wheezing }\end{array}$ & 2 & 0 & Not provided \\
\hline & Respiratory rate & 1 & 0 & Not provided \\
\hline & $\begin{array}{l}\text { St Georges respiratory } \\
\text { questionnaire (SGRQ) }\end{array}$ & 4 & 1 & Not provided \\
\hline & $\begin{array}{l}\text { Time to improvement of } \\
\text { abnormalities in Chest radiology }\end{array}$ & 1 & 1 & 28 days \\
\hline & $\begin{array}{l}\text { The incidence of dyspnea with } \\
\text { low oxygen saturation level and } \\
\text { high respiratory rate }\end{array}$ & 1 & 1 & 28 days \\
\hline & $\begin{array}{l}\text { Time of improvement in } \\
\text { respiratory symptoms }\end{array}$ & 1 & 0 & Not provided \\
\hline Functioning & & & & \\
\hline
\end{tabular}

Physical functioning

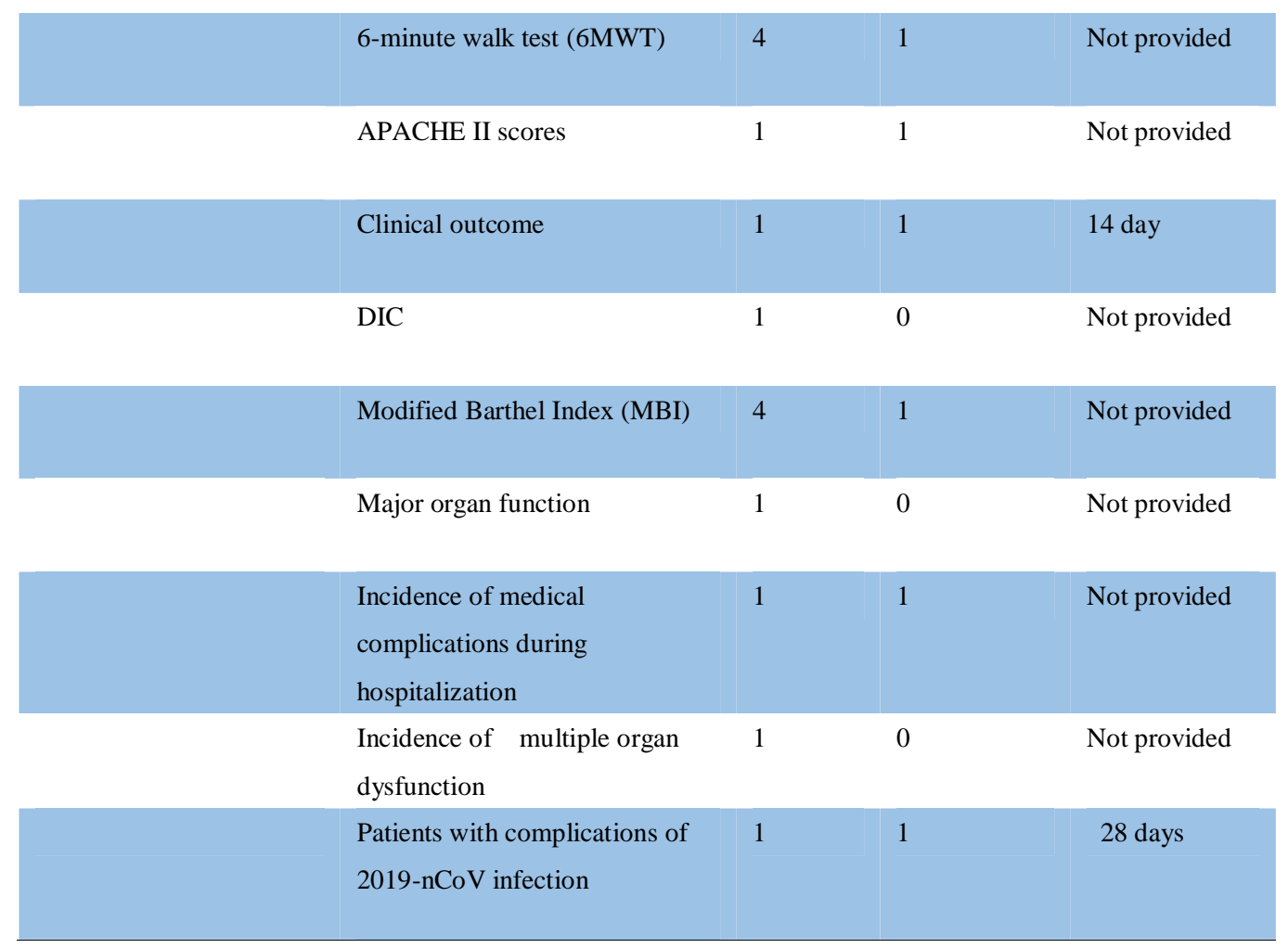


medRxiv preprint doi: https://doi.org/10.1101/2020.03.04.20031401; this version posted March 8, 2020. The copyright holder for this preprint (which was not certified by peer review) is the author/funder, who has granted medRxiv a license to display the preprint in perpetuity.

All rights reserved. No reuse allowed without permission.

\begin{tabular}{|l|l|l|l}
\hline Outcome domain & $\begin{array}{l}\text { Number } \\
\text { of } \\
\text { outcomes }\end{array}$ & $\begin{array}{l}\text { Defination/ } \\
\text { outcome } \\
\text { measurement }\end{array}$ & Time point \\
\hline Recovery rate & 2 & 0 & Not provided \\
\hline SOFA score & 1 & 1 & Not provided \\
\hline $\begin{array}{l}\text { Time to disease recovery } \\
\text { Time to release from isolation }\end{array}$ & 2 & 0 & Not provided \\
\hline Time to Clinical Recovery & 1 & 1 & Not provided \\
\hline
\end{tabular}

Global quality of life

\begin{tabular}{|l|l|l|l|}
\hline EQ-5D & 1 & 1 & Not provided \\
\hline SF-36 & 2 & 1 & Not provided \\
\hline Resource use & & & \\
\hline
\end{tabular}

Hospital

\begin{tabular}{|l|l|l|l|}
\hline Duration of hospitalization & 10 & 1 & 28 days \\
\hline Length of stay in ICU & 1 & 0 & Not provided
\end{tabular}

\begin{tabular}{|l|l|l|l|l|}
\hline $\begin{array}{l}\text { Need for further } \\
\text { intervention }\end{array}$ & \multicolumn{1}{|c|}{ Not provided } \\
\hline $\begin{array}{l}\text { The time when the condition } \\
\text { becomes worse }\end{array}$ & 6 & 3 & Not provided \\
\hline $\begin{array}{l}\text { Rate of progressing to the severe } \\
\text { stage }\end{array}$ & 7 & 1 & 1 & Not provided \\
\hline $\begin{array}{l}\text { Rate of progressing to the } \\
\text { critical stage }\end{array}$ & 10 & & \\
\hline Adverse events/effects & $\begin{array}{l}\text { Adverse events } \\
\text { Ad }\end{array}$ & 9 & 0 & Not provided \\
\hline
\end{tabular}

CRP: C-reactive protein; CURB-65: Confusion, Urea, Respiratory Rate and Age 65; ECG: electrocardiogram;

HLA-DR: Human leukocyte antigen-DR; HRCT: chest high-resolution computed tomography; ICU: Intensive Care Unit; RNA: ribonucleic acid; SARS-CoV-2: Severe Acute Respiratory Syndrome Coronavirus 2; SOFA: Sequential Organ Failure Assessment; TCM: traditional Chinese medicine. 
medRxiv preprint doi: https://doi.org/10.1101/2020.03.04.20031401; this version posted March 8, 2020. The copyright holder for this preprint (which was not certified by peer review) is the author/funder, who has granted medRxiv a license to display the preprint in perpetuity.

All rights reserved. No reuse allowed without permission.

Table 5 Outcomes from protocols of western medicine clinical trials

\begin{tabular}{|c|c|c|c|c|}
\hline Outcome domain & Outcomes & $\begin{array}{l}\text { Number } \\
\text { of } \\
\text { outcomes }\end{array}$ & $\begin{array}{c}\text { Definition/ } \\
\text { outcome } \\
\text { measurement }\end{array}$ & Time point \\
\hline \multicolumn{5}{|l|}{ Mortality/survival } \\
\hline & Mortality/survival & 36 & 1 & $\begin{array}{l}2 \text { weeks, } 4 \text { weeks, } \\
12 \text { weeks, } 14-20 \\
\text { days, } 28 \text { days. }\end{array}$ \\
\hline
\end{tabular}

\section{Physiological/clinical}

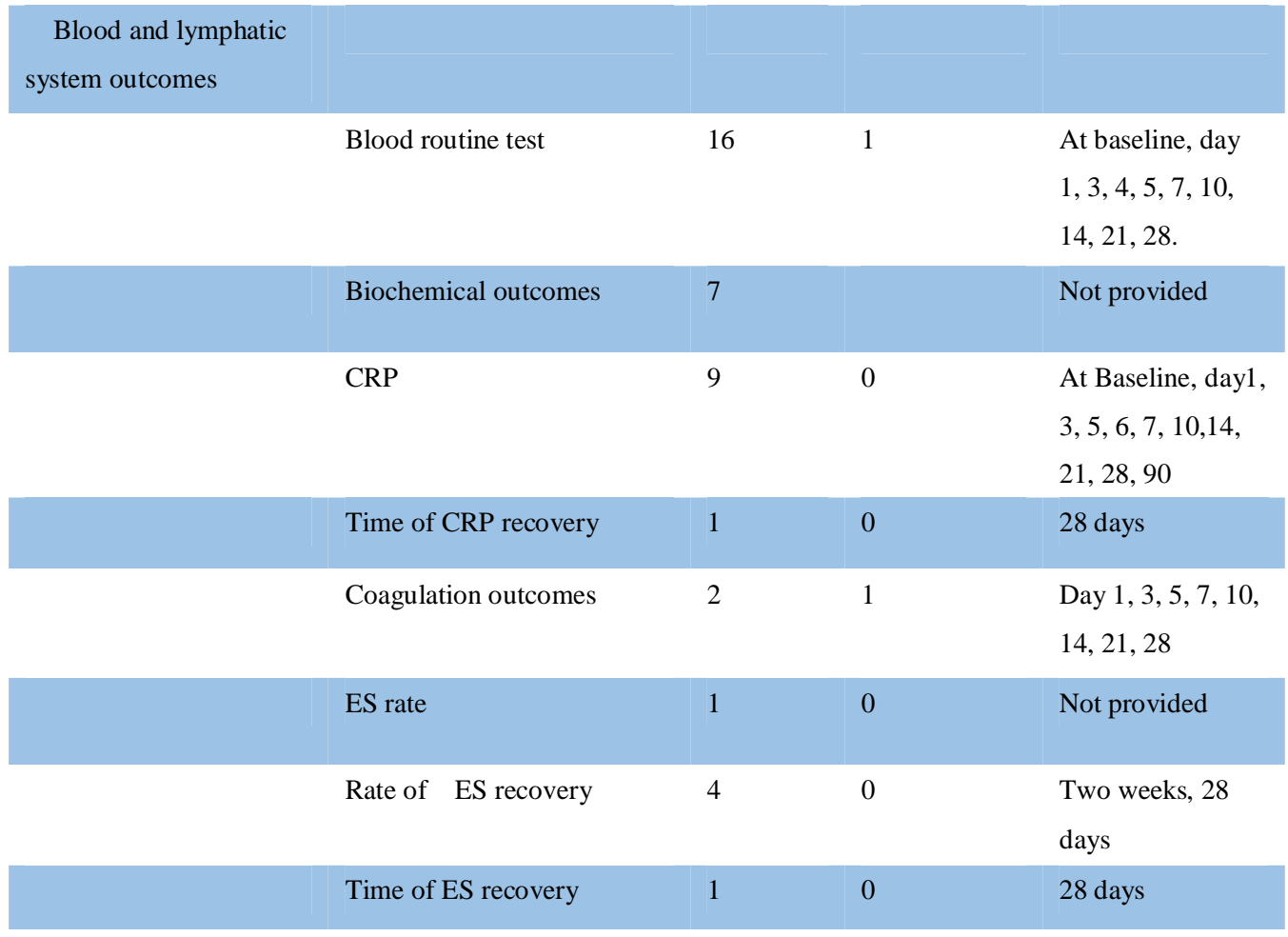

Cardiac outcomes

\begin{tabular}{l|l|l|l}
\hline ECG & 3 & 1 & Not provided \\
\hline Heart rate & 6 & 0 & Baseline, week 1, \\
& & & week 2, week 3, \\
& & week 4 \\
\hline Myocardial enzymes & 2 & 0 & Day 0, 3, 4, 6, 7, \\
& & & $10,14,28,90$ \\
\hline
\end{tabular}


medRxiv preprint doi: https://doi.org/10.1101/2020.03.04.20031401; this version posted March 8, 2020. The copyright holder for this preprint (which was not certified by peer review) is the author/funder, who has granted medRxiv a license to display the preprint in perpetuity.

All rights reserved. No reuse allowed without permission.

\begin{tabular}{|c|c|c|c|c|}
\hline Outcome domain & Outcomes & $\begin{array}{l}\text { Number } \\
\text { of } \\
\text { outcomes }\end{array}$ & $\begin{array}{c}\text { Definition/ } \\
\text { outcome } \\
\text { measurement }\end{array}$ & Time point \\
\hline & $\mathrm{Mb}$ & 1 & 0 & $\begin{array}{l}\text { Day } 1,3,5,7,10, \\
14,21,28\end{array}$ \\
\hline & Rate of $\mathrm{Mb}$ recovery & 4 & 0 & $\begin{array}{l}\text { Two weeks, } 28 \\
\text { days }\end{array}$ \\
\hline & Rate of CK recovery & 4 & 0 & $\begin{array}{l}\text { Two weeks, } 28 \\
\text { days }\end{array}$ \\
\hline & Time of Mb recovery & 1 & 0 & 28 days \\
\hline & Time of CK recovery & 1 & 0 & 28 days \\
\hline
\end{tabular}

\begin{tabular}{|c|c|c|c|c|}
\hline General outcomes & & & & \\
\hline & $\begin{array}{l}\text { Abnormal time of } \\
\text { temperature during infection }\end{array}$ & 1 & 0 & Not provided \\
\hline & Antipyretic rate & 2 & 1 & 14-20 days \\
\hline & Blood pressure & 6 & 0 & Day 0 till day 21 \\
\hline & Clearance time of fever & 15 & 0 & $\begin{array}{l}14-20 \text { days, up to } \\
28 \text { days }\end{array}$ \\
\hline & Clearance time of fatigue & 6 & 0 & Not provided \\
\hline & Clearance time of myalgia & 2 & 0 & 14-20 days \\
\hline & $\begin{array}{l}\text { Proportion of patients } \\
\text { without fatigue }\end{array}$ & 6 & 0 & Not provided \\
\hline & $\begin{array}{l}\text { Proportion of patients } \\
\text { without dyspnea }\end{array}$ & 5 & 0 & 14 days \\
\hline & $\begin{array}{l}\text { Proportion of patients } \\
\text { without fever }\end{array}$ & 14 & 0 & $\begin{array}{l}\text { Day } 7 \text {, within } 14 \\
\text { days }\end{array}$ \\
\hline & Temperature & 6 & 0 & $\begin{array}{l}\text { Baseline, } 1 \text { week, } \\
2 \text { weeks, } 3 \text { weeks, } \\
4 \text { weeks }\end{array}$ \\
\hline
\end{tabular}

Hepatobiliary

outcomes

\begin{tabular}{|l|l|l|l}
\hline ALT & 1 & 0 & $\begin{array}{l}\text { At baseline, day } \\
3,6,10,14,28 \\
\text { and } 90\end{array}$ \\
\hline Rate of ALT recovery & 4 & 0 & $\begin{array}{l}\text { Two weeks, } 28 \\
\text { days }\end{array}$ \\
\hline Time to ALT recovery & 1 & 0 & 28 days \\
\hline
\end{tabular}


medRxiv preprint doi: https://doi.org/10.1101/2020.03.04.20031401; this version posted March 8, 2020. The copyright holder for this preprint (which was not certified by peer review) is the author/funder, who has granted medRxiv a license to display the preprint in perpetuity.

All rights reserved. No reuse allowed without permission.

\begin{tabular}{|c|c|c|c|c|}
\hline Outcome domain & Outcomes & $\begin{array}{l}\text { Number } \\
\text { of } \\
\text { outcomes }\end{array}$ & $\begin{array}{c}\text { Definition/ } \\
\text { outcome } \\
\text { measurement }\end{array}$ & Time point \\
\hline
\end{tabular}

Immune system

$$
\text { outcomes }
$$

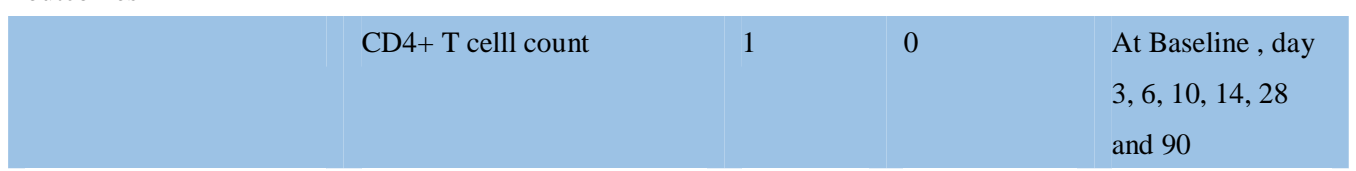

CD8+ T celll count $\quad 1 \quad 0 \quad$ At Baseline, day

$3,6,10,14,28$

and 90

$\begin{array}{llll}\text { IL-2 } & 1 & 0 & \text { Day 7, 14, } 28\end{array}$

\begin{tabular}{|l|l|l|l|}
\hline IL-4 & 1 & 0 & Day 7, 14, 28 \\
\hline IL-6 & 8 & 0 & $\begin{array}{l}\text { Day } 1,3,5,7,10, \\
14,21,28\end{array}$ \\
\hline IL-8 & 1 & 0 & On the Day 28
\end{tabular}

$\begin{array}{llll}\text { IL-10 } & 1 & 0 & \text { Day 7, 14, } 28\end{array}$

\begin{tabular}{|l|l|l|l}
\hline $\begin{array}{l}\text { Immunoglobulin } \\
\text { Lymphocyte subsets and }\end{array}$ & 1 & 0 & Not provided \\
\hline $\begin{array}{l}\text { complement } \\
\text { Pom }\end{array}$ & & & Day 1, 3, 5, 7, 10, \\
\hline
\end{tabular}

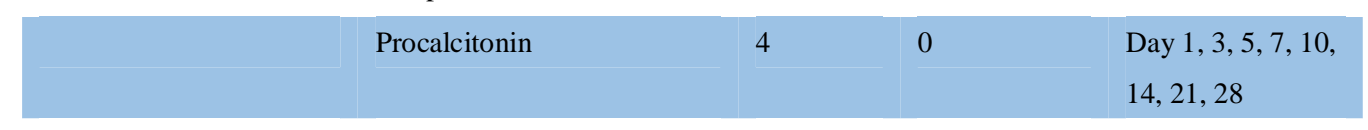

\begin{tabular}{|l|c|c|c|}
\hline $\begin{array}{l}\text { Recovery time of } \\
\text { lymphocyte }\end{array}$ & 1 & 0 & Not provided \\
\hline $\begin{array}{l}\text { Time to CD4+ T cell } \\
\text { recovery }\end{array}$ & 1 & 0 & Not provided \\
\hline $\begin{array}{l}\text { Time to CD8+ T cell } \\
\text { recovery }\end{array}$ & 1 & 0 & Not provided \\
\hline TNF- $\alpha$ & 4 & 0 & Day 7, 14, 28 \\
\hline$\gamma$-interferon & 1 & 0 & Day 7,14, 28
\end{tabular}

\section{Infection and} infestation outcomes

\begin{tabular}{|c|c|c|c|}
\hline $\begin{array}{l}\text { Chloroquine blood } \\
\text { concentration }\end{array}$ & 1 & 0 & $\begin{array}{l}\text { Day } 1,3,5,7,10, \\
14,21,28\end{array}$ \\
\hline
\end{tabular}

\begin{tabular}{|l|l|l|l|}
\hline $\begin{array}{l}\text { Declining speed of } \\
\text { SARS-CoV-2 }\end{array}$ & 1 & 1 & Not provided \\
\hline $\begin{array}{l}\text { Duration of antibiotic } \\
\text { treatment }\end{array}$ & 1 & 0 & Not provided \\
\hline
\end{tabular}


medRxiv preprint doi: https://doi.org/10.1101/2020.03.04.20031401; this version posted March 8, 2020. The copyright holder for this preprint (which was not certified by peer review) is the author/funder, who has granted medRxiv a license to display the preprint in perpetuity.

All rights reserved. No reuse allowed without permission.

\begin{tabular}{|c|c|c|c|c|}
\hline Outcome domain & Outcomes & $\begin{array}{l}\text { Number } \\
\text { of } \\
\text { outcomes }\end{array}$ & $\begin{array}{c}\text { Definition/ } \\
\text { outcome } \\
\text { measurement }\end{array}$ & Time point \\
\hline & Hemodiafiltration & 1 & 0 & Not provided \\
\hline & $\begin{array}{l}\text { Incidence of antibiotic } \\
\text { treatment }\end{array}$ & 2 & 0 & Not provided \\
\hline & $\begin{array}{l}\text { Level of virus antibody in } \\
\text { blood sample }\end{array}$ & 1 & 0 & Not provided \\
\hline & Other infection & 1 & 0 & Not provided \\
\hline & $\begin{array}{l}\text { Proportion of patients with } \\
\text { negative SARS-CoV-2 }\end{array}$ & 40 & 1 & $\begin{array}{l}\text { Day } 0,1,2,3,4 \text {, } \\
5,7,10,14,16, \\
21,28\end{array}$ \\
\hline & $\begin{array}{l}\text { Time of SARS-CoV-2 RNA } \\
\text { turns to negative }\end{array}$ & 23 & 1 & $\begin{array}{l}\text { At baseline, day } \\
3,6,7,10,14, \\
28,90\end{array}$ \\
\hline \multicolumn{5}{|l|}{$\begin{array}{l}\text { Metabolism and } \\
\text { nutrition outcomes }\end{array}$} \\
\hline & Liquid balance & 1 & 0 & Not provided \\
\hline \multicolumn{5}{|l|}{$\begin{array}{l}\text { Musculoskeletal and } \\
\text { connective tissue } \\
\text { outcomes }\end{array}$} \\
\hline & MRI of hip & 1 & 1 & Not provided \\
\hline & CT of hip & 1 & 1 & Not provided \\
\hline
\end{tabular}

Renal and urinary

outcomes

\begin{tabular}{|c|c|c|c|c|}
\hline & Urine routine & 1 & 0 & Not provided \\
\hline & kidney function & 2 & 1 & $\begin{array}{l}\text { Day } 0,1,3,4,5, \\
7,10,14,21,28\end{array}$ \\
\hline & $\begin{array}{l}\text { Incidence rate of kidney } \\
\text { damage }\end{array}$ & 1 & 0 & Not provided \\
\hline \multicolumn{5}{|l|}{$\begin{array}{l}\text { Respiratory, thoracic } \\
\text { and mediastinal } \\
\text { outcomes }\end{array}$} \\
\hline & $\begin{array}{l}\text { Application of pulmonary } \\
\text { surfactant }\end{array}$ & 1 & 0 & Not provided \\
\hline & Blood oxygen saturation & 2 & 0 & Day 0 till day 21 \\
\hline
\end{tabular}


medRxiv preprint doi: https://doi.org/10.1101/2020.03.04.20031401; this version posted March 8, 2020. The copyright holder for this preprint (which was not certified by peer review) is the author/funder, who has granted medRxiv a license to display the preprint in perpetuity.

All rights reserved. No reuse allowed without permission.

\begin{tabular}{|c|c|c|c|c|}
\hline Outcome domain & Outcomes & $\begin{array}{l}\text { Number } \\
\text { of } \\
\text { outcomes }\end{array}$ & $\begin{array}{c}\text { Definition/ } \\
\text { outcome } \\
\text { measurement }\end{array}$ & Time point \\
\hline & $\mathrm{PaO} 2 / \mathrm{FiO} 2$ & 7 & 1 & $\begin{array}{l}\text { Day } 1,3,5,7,10, \\
14,21,28\end{array}$ \\
\hline & Chest imaging & 25 & 2 & $\begin{array}{l}\text { At baseline, day } \\
3,4,6,7,10,14, \\
21,28\end{array}$ \\
\hline & Clearance time of cough & 9 & 0 & 14-20 days \\
\hline & Clearance time of dyspnea & 3 & 0 & $\begin{array}{l}\text { 14-20 days, up to } \\
28 \text { days }\end{array}$ \\
\hline & $\begin{array}{l}\text { Duration of extracorporeal } \\
\text { membrane oxygenation }\end{array}$ & 2 & 0 & Up to 28 days \\
\hline & $\begin{array}{l}\text { Duration of supplemental } \\
\text { oxygenation }\end{array}$ & 6 & 0 & Up to 28 days \\
\hline & $\begin{array}{l}\text { Duration of mechanical } \\
\text { ventilation }\end{array}$ & 10 & 0 & $\begin{array}{l}\text { From Day } 0 \\
\text { through Day } 28\end{array}$ \\
\hline & $\begin{array}{l}\text { Finger oxygen improvement } \\
\text { rate }\end{array}$ & 2 & 1 & 14-20 days \\
\hline & $\begin{array}{l}\text { Frequency of requirement } \\
\text { for mechanical ventilation }\end{array}$ & 1 & 0 & Up to 28 days \\
\hline & $\begin{array}{l}\text { Frequency of requirement } \\
\text { for supplemental oxygen }\end{array}$ & 1 & 0 & 14 days, 28 days \\
\hline & $\begin{array}{l}\text { Frequency of respiratory } \\
\text { progression }\end{array}$ & 2 & 1 & Up to 28 days \\
\hline & Murray lung injury score & 5 & 1 & 7 days, 14 days \\
\hline & Oxygen intake methods & 1 & 1 & Up to 28 days \\
\hline & Pneumonia severity index & 2 & 0 & Not provided \\
\hline & $\begin{array}{l}\text { Proportion of patients } \\
\text { without cough }\end{array}$ & 12 & 0 & $\begin{array}{l}\text { Within } 14 \text { days, } \\
\text { up to } 28 \text { days }\end{array}$ \\
\hline & Respiratory rate & 6 & 1 & $\begin{array}{l}\text { Baseline, } 1 \text { week, } \\
2 \text { weeks, } 3 \text { weeks, } \\
\text { 4weeks }\end{array}$ \\
\hline & $\begin{array}{l}\text { Rate of mechanical } \\
\text { ventilation }\end{array}$ & 9 & 1 & Day $7,14,15$ \\
\hline & $\begin{array}{l}\text { Time to normalization of } \\
\text { respiratory rate }\end{array}$ & 1 & 0 & Not provided \\
\hline & The duration of intubation & 1 & 0 & Not provided \\
\hline
\end{tabular}


medRxiv preprint doi: https://doi.org/10.1101/2020.03.04.20031401; this version posted March 8, 2020. The copyright holder for this preprint (which was not certified by peer review) is the author/funder, who has granted medRxiv a license to display the preprint in perpetuity.

All rights reserved. No reuse allowed without permission.

\begin{tabular}{|c|c|c|c|c|}
\hline Outcome domain & Outcomes & $\begin{array}{l}\text { Number } \\
\text { of } \\
\text { outcomes }\end{array}$ & $\begin{array}{c}\text { Definition/ } \\
\text { outcome } \\
\text { measurement }\end{array}$ & Time point \\
\hline & The incidence of hypoxia & 1 & 0 & Not provided \\
\hline & $\begin{array}{l}\text { The lowest } \mathrm{SpO} 2 \text { during } \\
\text { intubation }\end{array}$ & 1 & 0 & Not provided \\
\hline & $\begin{array}{l}\text { Time to chest imaging } \\
\text { recovery }\end{array}$ & 2 & 1 & Two weeks \\
\hline & The times of intubation & 1 & 0 & Not provided \\
\hline & $\begin{array}{l}\text { Time of improvement in } \\
\text { respiratory symptoms }\end{array}$ & 2 & 0 & Not provided \\
\hline & $\begin{array}{l}\text { Time of using assisted } \\
\text { breathing }\end{array}$ & 2 & 0 & Not provided \\
\hline & $\begin{array}{l}\text { Time to cough reported as } \\
\text { mild }\end{array}$ & 1 & 0 & Not provided \\
\hline & $\begin{array}{l}\text { Time to dyspnea reported as } \\
\text { mild }\end{array}$ & 1 & 1 & Up to 28 days \\
\hline & $\begin{array}{l}\text { Rate of no requiring } \\
\text { supplemental oxygen }\end{array}$ & 11 & 0 & 14 days \\
\hline & Ventilator parameters & 5 & 1 & Day 10 and 28 \\
\hline Functioning & & & & \\
\hline
\end{tabular}

Physical functioning

\begin{tabular}{|l|l|l|l|}
\hline $\begin{array}{l}\text { 7-point scale } \\
\text { APACHE II scores }\end{array}$ & 1 & 1 & Not provided \\
\hline $\begin{array}{l}\text { Complications } \\
\text { Demand for first aid }\end{array}$ & 1 & 0 & Day 10 \\
\hline $\begin{array}{l}\text { measurements } \\
\text { Disease progression rate }\end{array}$ & 4 & 1 & On the day 28 \\
\hline $\begin{array}{l}\text { Incidence of multiple } \\
\text { organ dysfunction }\end{array}$ & 1 & 1 & $14-20$ days \\
\hline $\begin{array}{l}\text { Incidence of shock } \\
\text { Lower SOFA score }\end{array}$ & 1 & 0 & Not provided \\
\hline
\end{tabular}


medRxiv preprint doi: https://doi.org/10.1101/2020.03.04.20031401; this version posted March 8, 2020. The copyright holder for this preprint (which was not certified by peer review) is the author/funder, who has granted medRxiv a license to display the preprint in perpetuity.

All rights reserved. No reuse allowed without permission.

\begin{tabular}{|c|c|c|c|c|}
\hline Outcome domain & Outcomes & $\begin{array}{l}\text { Number } \\
\text { of } \\
\text { outcomes }\end{array}$ & $\begin{array}{c}\text { Definition/ } \\
\text { outcome } \\
\text { measurement }\end{array}$ & Time point \\
\hline & NEWS2 score & 1 & 1 & Not provided \\
\hline & $\begin{array}{l}\text { Number of participants with } \\
\text { improvement from severe } \\
\text { type to common type }\end{array}$ & 1 & 1 & 2 weeks \\
\hline & $\begin{array}{l}\text { Organ function support } \\
\text { measures }\end{array}$ & 1 & 0 & Not provided \\
\hline & Organ support intensity & 1 & 0 & Not provided \\
\hline & $\begin{array}{l}\text { Rate of severe type of } \\
\text { disease }\end{array}$ & 2 & 0 & Not provided \\
\hline & $\begin{array}{l}\text { Rate of preventing mild to } \\
\text { moderate patients from } \\
\text { shifting to severe patients }\end{array}$ & 1 & 0 & Not provided \\
\hline & Rate of disease remission & 5 & 1 & $\begin{array}{l}\text { Day } 7 \text {, within } 14 \\
\text { days }\end{array}$ \\
\hline & SOFA score & 3 & 1 & Day 7,10 \\
\hline & Time to treatment failure & 2 & 1 & Not provided \\
\hline & $\begin{array}{l}\text { Time to NEWS } 2 \text { of } \leq 2 \\
\text { maintained for } 24 \text { hours. }\end{array}$ & 1 & 0 & Up to 28 days \\
\hline & $\begin{array}{l}\text { Time to release from } \\
\text { isolation }\end{array}$ & 1 & 0 & Not provided \\
\hline & Time to severe stage & 2 & 0 & Not provided \\
\hline & The rate of critical stage & 3 & 1 & 2 weeks \\
\hline & Time to Clinical Recovery & 7 & 4 & 14 days, 28 days \\
\hline & $\begin{array}{l}\text { Time to Clinical } \\
\text { Improvement }\end{array}$ & 8 & 2 & Up to 28 days \\
\hline
\end{tabular}

Delivery of care

\begin{tabular}{l|l|l|l|}
$\begin{array}{l}\text { The rate of discontinuations } \\
\text { due to adverse events }\end{array}$ & 1 & 0 & Not provided \\
\hline
\end{tabular}

\section{Resource use}

\begin{tabular}{|l|l|l|l|l|}
\hline Economic & Hospitalization costs & 1 & 0 & Not provided \\
\hline
\end{tabular}

Hospital 
medRxiv preprint doi: https://doi.org/10.1101/2020.03.04.20031401; this version posted March 8, 2020. The copyright holder for this preprint (which was not certified by peer review) is the author/funder, who has granted medRxiv a license to display the preprint in perpetuity.

All rights reserved. No reuse allowed without permission.

\begin{tabular}{|c|c|c|c|c|}
\hline Outcome domain & Outcomes & $\begin{array}{l}\text { Number } \\
\text { of } \\
\text { outcomes }\end{array}$ & $\begin{array}{c}\text { Definition/ } \\
\text { outcome } \\
\text { measurement }\end{array}$ & Time point \\
\hline & Duration of hospitalization & 23 & 0 & $\begin{array}{l}\text { From day } 0 \\
\text { through day } 28\end{array}$ \\
\hline & Length of stay in ICU & 10 & 1 & Day 28 \\
\hline & ICU free days & 1 & 0 & Up to 28 days \\
\hline & Incidence of ICU admission & 9 & 0 & Day7, $14,15,28$ \\
\hline & The proportion of inpatients & 1 & 0 & Within 28 days \\
\hline
\end{tabular}

Need for further

intervention

\begin{tabular}{|l|l|l|l|l|}
\hline $\begin{array}{l}\text { The time when the condition } \\
\text { becomes worse }\end{array}$ & 5 & 1 & Not provided \\
\hline $\begin{array}{l}\text { Jaw thrust maneuver } \\
\text { Rate of progressing to the }\end{array}$ & 1 & 0 & 1 & Not provided \\
\hline $\begin{array}{l}\text { critical stage } \\
\text { Time to the critical stage }\end{array}$ & 1 & 1 & Day 7 \\
\hline
\end{tabular}

\begin{tabular}{|c|c|c|c|}
\hline \multicolumn{4}{|l|}{ Adverse events/effects } \\
\hline Adverse events & 29 & 5 & $\begin{array}{l}\text { At baseline, day } \\
3,6,10,14,28, \\
90\end{array}$ \\
\hline
\end{tabular}

APACHE-II: Acute Physiology and Chronic Health Evaluation; ALT: Alanine aminotransferase; CK: Creatine Kinase; CRP: C-reactive protein; ES: Erythrocyte sedimentation; ECG: electrocardiogram; ICU: Intensive Care Unit; IL: Interleukin; Mb: Myoglobin; NEWS2: National Early Warning Score 2; RNA: ribonucleic acid; SARS-CoV-2: Severe Acute Respiratory Syndrome Coronavirus 2; SOFA: Sequential Organ Failure Assessment.

\section{Contributors}

RQ and HS contributed to the study design. XW and MZ conducted searching and extracted data from databases. RQ, CZ, JH, YH, TH contributed to the data analysis. RQ drafted the manuscript. ML, HS, CZ, JC, HS revised the manuscript. All authors read and approved the final manuscript.

\section{Funding}

This work was supported by the National High-level Personnel of Special Support Program [W02020052].

\section{Competing interests}

The authors declare that there is no conflict of interest. 


\section{Patient consent}

Not required.

\section{Data sharing statement}

The data is from public database and does not include identifiable patient data.

References:

1. China Health Commission of the People's Republic of China. http://www.nhc.gov.cn/xcs/yqtb/202002/67e6c59a84bd4f07b6ca4a4c5ffabb79.shtml [Accessed 25 Feb 2020].

2. WHO.

https://www.who.int/docs/default-source/coronaviruse/situation-reports/20200225-sitrep-36-covid-19.pdf?sfvrsn= 2791b4e0_2 [Accessed 25 Feb 2020].

3. China Health Commission of the People's Republic of China. http://www.nhc.gov.cn/yzygj/s7653p/202002/8334a8326dd94d329df351d7da8aefc2/files/b218cfeb1bc54639af227 f922bf6b817.pdf [Accessed 25 Feb 2020].

4. Shang H, Qiu R. http://www.comet-initiative.org/Studies/Details/1507 [Accessed 20 Feb 2020].

5. Huang C. A randomized, open-label, blank-controlled trial for the efficacy and safety of lopinavir-ritonavir and interferon-alpha $2 \mathrm{~b}$ in hospitalization patients with novel coronavirus pneumonia (COVID-19). Available: http://www.comet-initiative.org/Studies/Details/1507 [Accessed 14 Feb 2020].

6. ICMJE. Which trials registries are acceptable to the ICMJE? http://www.icmje.org/about-icmje/faqs/clinical-trials-registration/ [Accessed 14 Feb 2020].

7. Dodd S, Clarke M, Becker L, et al. A taxonomy has been developed for outcomes in medical research to help improve knowledge discovery. J Clin Epidemiol 2018, 96:84-92.

8. Zhong N, Song Y, Qiu H, Li Y, Liu X. A prospective comparative study for Xue-Bi-Jing injection in the treatment of novel coronavirus pneumonia (COVID-19). http://www.chictr.org.cn/showproj.aspx?proj=48768 [Accessed 14 Feb 2020].

9. Huang L. Clinical Controlled Trial for Traditional Chinese Medicine in the treatment of Novel Coronavirus Pneumonia (COVID-19). http://www.chictr.org.cn/showproj.aspx?proj=48824 [Accessed 14 Feb 2020].

10. Liang $\mathrm{T}$, Wang $\mathrm{T}$, Hao $\mathrm{X}$, et al. Chinese Herbal medicine for Severe nevel coronavirus pneumonia (COVID-19): a Randomized Controlled Trial. http://www.chictr.org.cn/showproj.aspx?proj=48886 [Accessed 14 Feb 2020].

11. Liu Q, Miao Q, Zhang B. A randomized controlled trial of integrated TCM and Western Medicine in the treatment of severe novel coronavirus pneumonia (COVID-19). http://www.chictr.org.cn/showproj.aspx?proj=48911 [Accessed 14 Feb 2020].

12. Xia W, An C, Zhang B. A single arm study for combination of traditional Chinese and Western Medicine in the treatment of novel coronavirus pneumonia (COVID-19). http://www.chictr.org.cn/showproj.aspx ?proj=48913 [Accessed 14 Feb 2020].

13. Wang Y, Li X, Zhang B. Combination of traditional Chinese medicine and western medicine in the treatment of common type novel coronavirus pneumonia (COVID-19). http://www.chictr.org.cn/showproj.aspx ?proj=48904 [Accessed 14 Feb 2020].

14. Li J, Li S. A single arm study for evaluation of integrated traditional Chinese and western medicine in the treatment of novel coronavirus pneumonia (COVID-19). http://www.chictr.org.cn/showproj.aspx ?proj=48884 [Accessed 14 Feb 2020].

15. Zhong N, Zhang B, Li J, et al. A randomized, open-label, blank-controlled trial for Lian-Hua Qing-Wen Capsule/Granule in the treatment of novel coronavirus pneumonia (COVID-19). 
http://www.chictr.org.cn/showproj.aspx?proj=48889 [Accessed 14 Feb 2020].

16. Yang Z, Wen M. A Real World Study for the Efficacy and Safety of Large Dose Tanreqing Injection in the Treatment of Patients with Novel Coronavirus Pneumonia (COVID-19). http://www.chictr.org.cn/showproj.aspx?proj=48881 [Accessed 14 Feb 2020].

17. Zhang J. Traditional Chinese Medicine for Pulmonary Fibrosis, Pulmonary Function and Quality of Life in Patients With Novel Coronavirus Pneumonia (COVID-19) in Convalescent Period: a Randomized Controlled Trial. http://www.chictr.org.cn/showproj.aspx?proj=48931 [Accessed 14 Feb 2020].

18. Zheng C. The effect of shadowboxing for pulmonary function and quality of life in patients with novel coronavirus pneumonia (COVID-19) in rehabilitation period. http://www.chictr.org.cn/showproj.aspx ?proj=48930 [Accessed $14 \mathrm{Feb} 2020]$.

19. Xia W. The effect of pulmonary rehabilitation for pulmonary function and quality of life in patients with novel coronavirus pneumonia (COVID-19) in rehabilitation period. http://www.chictr.org.cn/showproj.aspx?proj=48929 [Accessed 14 Feb 2020].

20. Xia W. A randomized controlled trial for integrated traditional Chinese medicine and western medicine in the Treatment of Common Type Novel Coronavirus Pneumonia (COVID-19). http://www.chictr.org.cn/showproj.aspx?proj=48927 [Accessed 14 Feb 2020].

21. Wen C. Chinese medicine prevention and treatment program for novel coronavirus pneumonia (COVID-19): a perspective, double-blind, placebo, randomised controlled trial. http://www.chictr.org.cn/showproj.aspx?proj=48860 [Accessed $14 \mathrm{Feb} 2020$ ].

22. Xie C. Recommendations of Integrated Traditional Chinese and Western Medicine for Novel Coronavirus Pneumonia (COVID-19). http://www.chictr.org.cn/showproj.aspx?proj=49014 [Accessed 14 Feb 2020].

23. Xie C. Recommendations of Integrated Traditional Chinese and Western Medicine for Diagnosis and Treatment of Novel Coronavirus Pneumonia (COVID-19) in Sichuan Province. http://www.chictr.org.cn/showproj.aspx?proj=48792 [Accessed 14 Feb 2020].

24. Wen C. Chinese medicine prevention and treatment program for novel coronavirus pneumonia (COVID-19): a perspective, sing-arm trial. http://www.chictr.org.cn/showproj.aspx?proj=49080 [Accessed 14 Feb 2020].

25. Liu Q. An open, prospective, multicenter clinical study for the efficacy and safety of Reduning injection in the treatment of ovel coronavirus pneumonia (COVID-19). http://www.chictr.org.cn/showproj.aspx?proj=49104 [Accessed 14 Feb 2020].

26. Wang D, Zhao J. A randomized, open-label, blank-controlled, multicenter trial for Shuang-Huang-Lian oral solution in the treatment of ovel coronavirus pneumonia (COVID-19). http://www.chictr.org.cn/showproj.aspx?proj=49051 [Accessed 14 Feb 2020].

27. Zhang Z. An observational study for Xin-Guan-1 formula in the treatment of novel coronavirus pneumonia (COVID-19). http://www.chictr.org.cn/showproj.aspx?proj=49127 [Accessed 14 Feb 2020].

28. Xiao X. Treatment and Prevention of Traditional Chinese Medicines (TCMs) on 2019-nCoV Infection.

29. Zhang N. Effect evaluation and prognosis of Chinese medicine based on Novel Coronavirus Pneumonia (COVID-19) . http://www.chictr.org.cn/showproj.aspx?proj=49287 [Accessed 14 Feb 2020].

30. Mao W. Clinical Study for Traditional Chinese Medicine in the Prevention and Treatment of Novel Coronavirus Pneumonia (COVID-19). http://www.chictr.org.cn/showproj.aspx?proj=49354 [Accessed 14 Feb 2020].

31. Liu D. A randomized, open, parallel-controlled clinical trial on the efficacy and safety of Jingyebaidu granules in treating novel coronavirus pneumonia (COVID-19). http://www.chictr.org.cn/showproj.aspx?proj=49301 [Accessed 14 Feb 2020].

32. Huang L, Li Z. The efficacy of traditional chinese medicine on Novel Coronavirus Pneumonia (COVID-19) 
patients treated in square cabin hospital: a prospective, randomized controlled trial. http://www.chictr.org.cn/showproj.aspx?proj=49408 [Accessed 14 Feb 2020].

33. Lv D. Babaodan Capsule used for the adjuvant treatment of Severe novel coronavirus pneumonia (COVID-19). http://www.chictr.org.cn/showproj.aspx?proj=49415 [Accessed 14 Feb 2020].

34. Huang T, Fang B, Feng J, et al. A multicenter, randomized, controlled trial for integrated chinese and western medicine in the treatment of novel coronavirus pneumonia (COVID-19) based on the 'Truncated Torsion' strategy. p://www.chictr.org.cn/showproj.aspx?proj=49380 [Accessed 14 Feb 2020].

35. Zhang W. Clinical Study for Traditional Chinese Medicine Combined With Western Medicine in Treatment of Novel Coronavirus Pneumonia (COVID-19). http://www.chictr.org.cn/showproj.aspx?proj=49422 [Accessed 14 Feb 2020].

36. Zheng X. A multicenter, randomized, open, controlled trial for the efficacy and safety of Shen-Qi Fu-Zheng injection in the treatment of novel coronavirus pneumonia (COVID-19). http://www.chictr.org.cn/showproj.aspx?proj=49220 [Accessed 14 Feb 2020].

37. Zheng X. A multicenter, randomized, open and controlled trial for the efficacy and safety of Kang-Bing-Du granules in the treatment of novel coronavirus pneumonia (COVID-19). http://www.chictr.org.cn/showproj.aspx?proj=49138 [Accessed 14 Feb 2020].

38. Zhang Y, Shang J. Traditional Chinese medicine cooperative therapy for patients with novel coronavirus pneumonia (COVID-19): a randomized controlled trial. http://www.chictr.org.cn/showproj.aspx ?proj=49452 [Accessed $14 \mathrm{Feb} 2020]$.

39. Wang L. Clinical study for the integration of traditional Chinese and western medicine in the treatment of novel coronavirus pneumonia (COVID-19). http://www.chictr.org.cn/showproj.aspx?proj=49453 [Accessed 14 Feb 2020].

40. Lu H, Chen X. Clinical Trial for Tanreqing Capsules in the Treatment of Novel Coronavirus Pneumonia (COVID-19). http://www.chictr.org.cn/showproj.aspx?proj=49425 [Accessed 14 Feb 2020].

41. Zhai X. Clinical Trial for Integrated Chinese and Western Medicine in the Treatment of Children with Novel Coronavirus Pneumonia (COVID-19). http://www.chictr.org.cn/showproj.aspx?proj=49387 [Accessed 14 Feb 2020].

42. Chen Y. Adjunctive Corticosteroid Therapy for Patients with Severe Novel Coronavirus Pneumonia (COVID-19): a Randomized Controlled Trial . http://www.chictr.org.cn/showproj.aspx?proj=48777 [Accessed 14 Feb 2020].

43. Zhao D. Clinical study for the remedy of M1 macrophages target in the treatment of novel coronavirus pneumonia (COVID-19) . . http://www.chictr.org.cn/showproj.aspx?proj=48907 [Accessed 14 Feb 2020].

44. Jiang H. A real-world study for lopinavir/ritonavir (LPV/r) and emtritabine (FTC) / Tenofovir alafenamide Fumarate tablets (TAF) regimen in the treatment of novel coronavirus pneumonia (COVID-19) . http://www.chictr.org.cn/showproj.aspx?proj=48919 [Accessed 14 Feb 2020].

45. Jiang S. Study for the efficacy of chloroquine in patients with novel coronavirus pneumonia (COVID-19). http://www.chictr.org.cn/showproj.aspx?proj=48968 [Accessed 14 Feb 2020].

46. Wang X, Ke H. A randomised, open, controlled trial for darunavir/cobicistat or Lopinavir/ritonavir combined with thymosin a1 in the treatment of novel coronavirus pneumonia (COVID-19)

http://www.chictr.org.cn/showproj.aspx?proj=48992 [Accessed 14 Feb 2020].

47. Zhao J. A randomized, open-label study to evaluate the efficacy and safety of Lopinavir-Ritonavir in patients with mild novel coronavirus pneumonia (COVID-19) http://www.chictr.org.cn/showproj.aspx ?proj=48991 [Accessed 14 Feb 2020].

48. Gong G. A randomized, open label, parallel controlled trial for evaluating the efficacy of recombinant 
cytokine gene-derived protein injection in eliminating novel coronavirus in patients with novel coronavirus pneumonia (COVID-19) . http://www.chictr.org.cn/showproj.aspx?proj=48809 [Accessed 14 Feb 2020].

49. Qiu Y. Randomized, open-label, controlled trial for evaluating of the efficacy and safety of Baloxavir Marboxil, Favipiravir, and Lopinavir-Ritonavir in the treatment of novel coronavirus pneumonia (COVID-19) patients . http://www.chictr.org.cn/showproj.aspx?proj=49015 [Accessed 14 Feb 2020].

50. Zhang $Z$. Therapeutic effect of hydroxychloroquine on novel coronavirus pneumonia (COVID-19) http://www.chictr.org.cn/showproj.aspx?proj=48880 [Accessed 14 Feb 2020].

51. Lv Q. A multicenter, randomized, open-label, positive-controlled trial for the efficacy and safety of recombinant cytokine gene-derived protein injection combined with abidole, lopinavir/litonavir in the treatment of novel coronavirus pneumonia (COVID-19) patients . . http://www.chictr.org.cn/showproj.aspx ?proj=49065 [Accessed $14 \mathrm{Feb} 2020]$.

52. Zhou J. A prospective, single-blind, randomized controlled trial for Ruxolitinib combined with mesenchymal stem cell infusion in the treatment of patients with severe novel coronavirus pneumonia (COVID-19) . http://www.chictr.org.cn/showproj.aspx?proj=49088 [Accessed 14 Feb 2020].

53. Qiu Y. A Randomized, Open-Label, Multi-Centre Clinical Trial Evaluating and Comparing the Safety and Efficiency of ASC09/Ritonavir and Lopinavir/Ritonavir for Confirmed Cases of Novel Coronavirus Pneumonia (COVID-19) . http://www.chictr.org.cn/showproj.aspx?proj=49075 [Accessed 14 Feb 2020].

54. Liu Y. Clinical study for safety and efficacy of Favipiravir in the treatment of novel coronavirus pneumonia (COVID-19) . http://www.chictr.org.cn/showproj.aspx?proj=49042 [Accessed 14 Feb 2020].

55. Chen Y. Comparison of efficacy and safety of three antiviral regimens in patients with mild to moderate novel coronavirus pneumonia (COVID-19): a randomized controlled trial. http://www.chictr.org.cn/showproj.aspx?proj=48782 [Accessed 14 Feb 2020].

56. Shan H. A prospective, open-label, multiple-center study for the efficacy of chloroquine phosphate in patients with novel coronavirus pneumonia (COVID-19) . http://www.chictr.org.cn/showproj. $\operatorname{aspx}$ ?proj=49145 [Accessed 14 Feb 2020].

57. Pei B. Safety and efficacy of umbilical cord blood mononuclear cells in the treatment of severe and critically novel coronavirus pneumonia(COVID-19): a randomized controlled clinical trial. http://www.chictr.org.cn/showproj.aspx?proj=41760 [Accessed 14 Feb 2020].

58. Pei B. Safety and efficacy of umbilical cord blood mononuclear cells conditioned medium in the treatment of severe and critically novel coronavirus pneumonia (COVID-19): a randomized controlled trial. http://www.chictr.org.cn/showproj.aspx?proj=49062 [Accessed 14 Feb 2020].

59. Qiu Y. A randomized controlled trial for the efficacy and safety of Baloxavir Marboxil, Favipiravir tablets in novel coronavirus pneumonia (COVID-19) patients who are still positive on virus detection under the current antiviral therapy. http://www.chictr.org.cn/showproj.aspx?proj=49013 [Accessed 14 Feb 2020].

60. $\mathrm{Hu} \mathrm{B}, \mathrm{Li}$ W. Efficacy and safety of aerosol inhalation of vMIP in the treatment of novel coronavirus pneumonia (COVID-19): a single arm clinical trial. http://www.chictr.org.cn/showproj. aspx?proj=49215

[Accessed 14 Feb 2020].

61. Liu L. Multicenter randomized controlled trial for novel recombinant high-efficiency compound interferon in the treatment of novel coronavirus pneumonia (COVID-19). http://www.chictr.org.cn/showproj.aspx? proj=49224 [Accessed $14 \mathrm{Feb} 2020]$.

62. Li L, Xu X, Xiang C. Clinical Study for Human Menstrual Blood-Derived Stem Cells in the Treatment of Acute Novel Coronavirus Pneumonia (COVID-19). http://www.chictr.org.cn/showproj.aspx?proj=49146 [Accessed 14 Feb 2020].

63. Wu C. Nasal high-fow preoxygenation assisted fibre-optic bronchoscope intubation in patients with critical 
novel coronavirus pneumonia (COVID-19) . http://www.chictr.org.cn/showproj. aspx?proj=49074 [Accessed 14 Feb 2020].

64. Du R. A randomized, open-label study to evaluate the efficacy and safety of low-dose corticosteroids in hospitalized patients with novel coronavirus pneumonia (COVID-19). http://www.chictr.org.cn/showproj.aspx?proj=49086 [Accessed 14 Feb 2020].

65. Qu J. Clinical study of arbidol hydrochloride tablets in the treatment of novel coronavirus pneumonia (COVID-19). http://www.chictr.org.cn/showproj.aspx?proj=49165 [Accessed 14 Feb 2020].

66. Unclear. Glucocorticoid Therapy for Critically Ill Patients With Severe Acute Respiratory Infections Caused by Noval Coronovirus 2019-nCoV: a Prospective, Randomized Controlled Trial. https://clinicaltrials.gov/ct2/show/record/NCT04244591 [Accessed 14 Feb 2020].

67. Lu H. Efficacy and Safety of Darunavir and Cobicistat for Treatment of Pneumonia Caused by 2019-nCoV (DACO-nCoV) . https://clinicaltrials.gov/ct2/show/NCT04252274?cond=nCoV\&draw=1\&rank=6 [Accessed 14 Feb 2020].

68. Qin N. A Prospective,Randomized Controlled Clinical Study of Interferon Atomization in the 2019-nCoV Pneumonia. https://clinicaltrials.gov/ct2/show/NCT04254874?cond=nCoV\&draw=2\&rank=3 [Accessed 14 Feb 2020].

69. Qin N. A Prospective,Randomized Controlled Clinical Study of Antiviral Therapy in the 2019-nCoV Pneumonia. https://clinicaltrials.gov/ct2/show/NCT04255017?cond=nCoV\&draw=2\&rank=2 [Accessed 14 Feb 2020].

70. Cao B. Mild/Moderate 2019-nCoV Remdesivir RCT. https://clinicaltrials.gov/ct2/show/NCT04252664?cond $=\mathrm{nCoV} \&$ draw $=2 \&$ rank=1 [Accessed 14 Feb 2020].

71. Cao B. Severe 2019-nCoV Remdesivir RCT. https://clinicaltrials.gov/ct2/show/NCT04257656?cond=nCoV $\&$ draw $=2 \&$ rank=7 [Accessed 14 Feb 2020].

72. Qu J. Clinical Study of Arbidol Hydrochloride Tablets in the Treatment of Pneumonia Caused by Novel Coronavirus. https://clinicaltrials.gov/ct2/show/NCT04260594?cond=nCoV\&draw=2\&rank=6 [Accessed 14 Feb 2020].

73. Qin N. A Randomized,Open,Controlled Clinical Study to Evaluate the Efficacy of ASC09F and Ritonavir for 2019-nCoV Pneumonia. https://clinicaltrials.gov/ct2/show/NCT04261270?cond=nCoV\&draw=2\&rank=5 [Accessed $14 \mathrm{Feb} 2020]$.

74. Li T. The Efficacy of Intravenous Immunoglobulin Therapy for Severe 2019-nCoV Infected Pneumonia . https://clinicaltrials.gov/ct2/show/NCT04261426?cond=nCoV\&draw=2\&rank=2 [Accessed 14 Feb 2020].

75. Lu H. Efficacy and Safety of Hydroxychloroquine for Treatment of Pneumonia Caused by 2019-nCoV ( HC-nCoV ). https://clinicaltrials.gov/ct2/show/NCT04261517?cond=nCoV\&draw=3\&rank=13 [Accessed 14 Feb 2020].

76. Zhang Z. Efficacy of therapeutic effects of hydroxycholoroquine in novel coronavirus pneumonia $\begin{array}{lllll}\text { (COVID-19) } & \text { patients(randomized } & \text { control }\end{array}$ http://www.chictr.org.cn/showproj.aspx?proj=49317 [Accessed 14 Feb 2020].

77. Xia J. Efficacy of Chloroquine and Lopinavir/ Ritonavir in mild/general novel coronavirus (CoVID-19) infections: a prospective, open-label, multicenter randomized controlled clinical study. http://www.chictr.org.cn/showproj.aspx?proj=49263 [Accessed 14 Feb 2020].

78. Ning Q, Han M. A randomized, parallel controlled trial for the efficacy and safety of Sodium Aescinate Injection in the treatment of patients with pneumonia (COVID-19). http://www.chictr.org.cn/showproj.aspx?proj=49297 [Accessed 14 Feb 2020]. 
79. Qin N. The Efficacy of Different Hormone Doses in 2019-nCoV Severe Pneumonia. https://clinicaltrials.gov/ct2/show/NCT04263402?id=NCT04263402\&draw=2\&rank=1 [Accessed 14 Feb 2020].

80. Qiu Y. Evaluating and Comparing the Safety and Efficiency of ASC09/Ritonavir and Lopinavir/Ritonavir for Novel Coronavirus Infection .

https://clinicaltrials.gov/ct2/show/NCT04261907?id=NCT04261907\&draw=2\&rank

$=1$ [Accessed 14 Feb 2020].

81. Li L. The Efficacy of Lopinavir Plus Ritonavir and Arbidol Against Novel Coronavirus Infection (ELACOI). https://clinicaltrials.gov/ct2/show/NCT04252885?id=NCT04252885\&draw=2\&rank=1 [Accessed 14 Feb 2020].

82. Shi L, Wang F. Patients Infected With 2019 Novel Coronavirus .

https://clinicaltrials.gov/ct2/show/NCT04252118?id=NCT04252118\&draw=2\&rank=1 [Accessed 14 Feb 2020].

83. Zhang F. Washed Microbiota Transplantation for Patients With 2019-nCoV Infection. https:/clinicaltrials.gov/ct2/show/NCT04251767?cond=\%E2\%80\%9C2019-nCoV+OR+Novel+Coronavirus+OR+ $\mathrm{New}+$ Coronavirus+OR+NCP+OR+Novel+Coronavirus+Pneumonia+OR+COVID-19+OR+SARS-CoV-2+OR+ Wuhan+pneumonia\%E2\%80\%9D\&draw=2\&rank=10 [Accessed 14 Feb 2020].

84. Peng Z. Vitamin C Infusion for the Treatment of Severe 2019-nCoV Infected Pneumonia. $\mathrm{https}: / /$ clinicaltrials.gov/ct2/show/NCT04264533?cond=\%E2\%80\%9C2019-nCoV+OR+Novel+Coronavirus+OR+ $\mathrm{New}+$ Coronavirus+OR+NCP+OR+Novel+Coronavirus+Pneumonia+OR+COVID-19+OR+SARS-CoV-2+OR+ Wuhan+pneumonia\%E2\%80\%9D\&draw=2\&rank=12 [Accessed 14 Feb 2020].

85. Chen X. Treatment of Acute Severe 2019-nCoV Pneumonia With Immunoglobulin From Cured Patients . https://clinicaltrials.gov/ct2/show/NCT04264858?cond=2019-nCoV+OR+Novel+Coronavirus+OR+New+ Coronavirus+OR+NCP+OR+Novel+Coronavirus+Pneumonia+OR+COVID-19+OR+SARS-CoV-2+OR+Wuhan+ pneumonia\&draw=2\&rank=13 [Accessed 14 Feb 2020].

86. Zhang Z. Clinical study of nebulized Xiyanping injection in the treatment of novel coronavirus pneumonia (COVID-19). http://www.chictr.org.cn/showproj.aspx?proj=49222 [Accessed 14 Feb 2020].

87. Liu Z. Convalescent plasma for the treatment of severe novel coronavirus pneumonia (COVID-19): a prospective randomized controlled trial. http://www.chictr.org.cn/showproj.aspx?proj=49081 [Accessed 14 Feb 2020].

88. Kang Y. Cohort Study of Novel Coronavirus Pneumonia (COVID-19) Critical Ill Patients . http://www.chictr.org.cn/showproj.aspx?proj=49295 [Accessed 14 Feb 2020].

89. Hu P. A multicenter, randomized, open label, controlled trial for the efficacy and safety of ASC09/ Ritonavir compound tablets and Lopinavir/ Ritonavir (Kaletra) and Arbidol tablets in the treatm ent of novel coronavirus pneumonia (COVID-19). http://www.chictr.org.cn/showproj.aspx?proj=49352 [Accessed 14 Feb 2020].

90. Mao H. A study for the efficacy of hydroxychloroquine for mild and moderate COVID-19 infectious diseases . http://www.chictr.org.cn/showproj. aspx?proj=49369 [Accessed 14 Feb 2020].

91. Huang W. Clinical study on the safety and effectiveness of Hydroxychloroquine Sulfate tablets in the treatment of patients with novel coronavirus pneumonia (COVID-19). http://www.chictr.org.cn/showproj.aspx?proj=49400 [Accessed 14 Feb 2020].

92. Huang W. Clinical study for the effect and safety of hydroxychloroquine sulfate tablets in the treatment of patients with severe novel coronavirus pneumonia (COVID-19), http://www.chictr.org.cn/showproj.aspx?proj=49404 [Accessed 14 Feb 2020].

93. Xu X. A multicenter, randomized controlled trial for the efficacy and safety of tocilizumab in the treatment of new coronavirus pneumonia (COVID-19). http://www.chictr.org.cn/showproj.aspx?proj=49409 [Accessed 14 Feb 2020].

94. Lin J. A randomized, open, controlled trial for diammonium glycyrrhizinate enteric-coated capsules 
combined with vitamin $\mathrm{C}$ tablets in the treatment of common novel coronavirus pneumonia (COVID-19) in the basic of clinical standard antiviral treatment to evaluate the safety and efficiency .

http://www.chictr.org.cn/showproj.aspx?proj=49

131 [Accessed 14 Feb 2020].

95. Huang X. A randomized, open-label, blank-controlled, multicenter trial for Polyinosinic-Polycytidylic Acid Injection in the treatment of novel coronavirus pneumonia (COVID-19). http://www.chictr.org.cn/showproj.aspx?proj=49342 [Accessed 14 Feb 2020].

96. Wu W. Clinical Application of ECMO in the Treatment of Patients with Very Serious Respiratory Failure due to novel Coronavirus Pneumonia (COVID-19). http://www.chictr.org.cn/showproj.aspx ?proj=49178 [Accessed 14 Feb 2020].

97. Xia J. Immunomodulatory Therapy for Severe Novel Coronavirus Pneumonia (COVID-19). http://www.chictr.org.cn/showproj.aspx?proj=49161 [Accessed 14 Feb 2020].

98. Xu C. Clinical Study for Anti-aging Active Freeze-dried Powder Granules in the Treatment of Acute Novel Coronavirus Pneumonia (COVID-19). http://www.chictr.org.cn/showproj.aspx?proj=49355 [Accessed 14 Feb 2020].

99. Xu C. Clinical Study for Umbilical Cord Blood Mononuclear Cells in the Treatment of Acute Novel Coronavirus Pneumonia (COVID-19) . http://www.chictr.org.cn/showproj.aspx?proj=49374 [Accessed 14 Feb 2020].

100. Xu C. Clinical Study for Cord Blood Mesenchymal Stem Cells in the Treatment of Acute Novel Coronavirus Pneumonia (COVID-19) . http://www.chictr.org.cn/showproj.aspx?proj=49389 [Accessed 14 Feb 2020].

101. Xu C. Clinical Study of Cord Blood NK Cells Combined with Cord Blood Mesenchymal Stem Cells in the

$\begin{array}{lllll}\text { Treatment } & \text { Acute } & \text { Novel }\end{array}$ http://www.chictr.org.cn/showproj.aspx?proj=49384 [Accessed 14 Feb 2020].

102. Xie J. Immunoregulatory Therapy for 2019-nCoV. https://clinicaltrials.gov/ct2/show/NCT04268537?cond $=\% 222019-\mathrm{nCoV} \% 22+\mathrm{OR}+\% 22 \mathrm{Novel}+\mathrm{Coronavirus} \% 22+\mathrm{OR}+\% 22 \mathrm{New}+\mathrm{Coronavirus} \% 22+\mathrm{OR}+\% 22 \mathrm{SARS}-\mathrm{CoV}-$ $2 \% 22 \mathrm{OR}+\% 22 \mathrm{SARI} \% 22 \mathrm{OR}+\% 22 \mathrm{NCP} \% 22+\mathrm{OR}+\% 22 \mathrm{Novel+Coronavirus+Pneumonia} \% 22+\mathrm{OR}+\% 22 \mathrm{COVID}-19$ $\% 22++\mathrm{OR}+\% 22 \mathrm{Wuhan}+$ pneumonia\%22\&draw=2\&ra [Accessed $14 \mathrm{Feb} 2020]$.

103. Peng Z. Umbilical Cord(UC)-Derived Mesenchymal Stem Cells(MSCs) Treatment for the 2019-novel Coronavirus(nCOV)

Pneumonia https://clinicaltrials.gov/ct2/show/NCT04269525?cond=\%222019-nCoV\%22+OR+\%22Novel+Coronavirus\%22+ $\mathrm{OR}+\% 22 \mathrm{New}+$ Coronavirus $\% 22+\mathrm{OR}+\% 22 \mathrm{SARS}-\mathrm{CoV}-2 \% 22 \mathrm{OR}+$

$\% 22 \mathrm{SARI} \% 22 \mathrm{OR}+\% 22 \mathrm{NCP} \% 22+\mathrm{OR}+\% 22 \mathrm{Novel}+\mathrm{Coronavirus+Pneumonia} \% 22+\mathrm{OR}+\% 22 \mathrm{COVID}-19 \% 22++\mathrm{OR}$ $+\% 22$ Wuhan+pneumonia\%22\&draw=3\&ra [Accessed $14 \mathrm{Feb} 2020]$. 
medRxiv preprint doi: https://doi.org/10.1101/2020.03.04.20031401; this version posted March 8, 2020. The copyright holder for this preprint (which was not certified by peer review) is the author/funder, who has granted medRxiv a license to display the preprint in perpetuity.

All rights reserved. No reuse allowed without permission.

Figure 1. The distribution of clinical trials

Figure 2. The number of outcomes in protocols of TCM clinical trials

Figure 3. The number of outcomes in protocols of western medicine clinical trials

Figure 4.The summary of outcome reporting for protocols of TCM clinical trials

Figure 5. The number of outcomes in different outcome domains in protocols of TCM clinical trials

Figure 6 . The summary of outcome reporting for protoclas of western medicine clinical trials

Figure 7. The number of outcomes in different outcome domains in protocols of western medicine clinical trials 
5

0 Anhui
Province

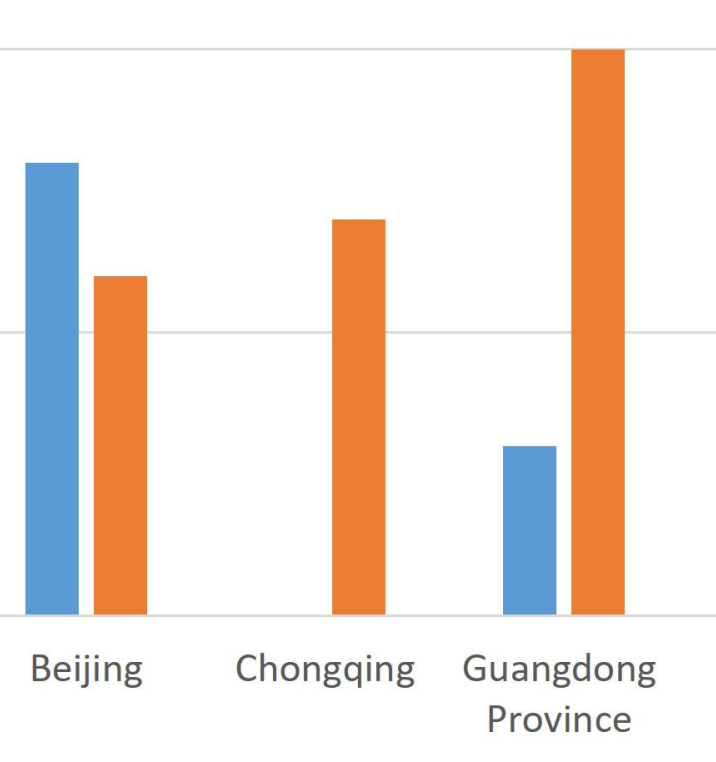

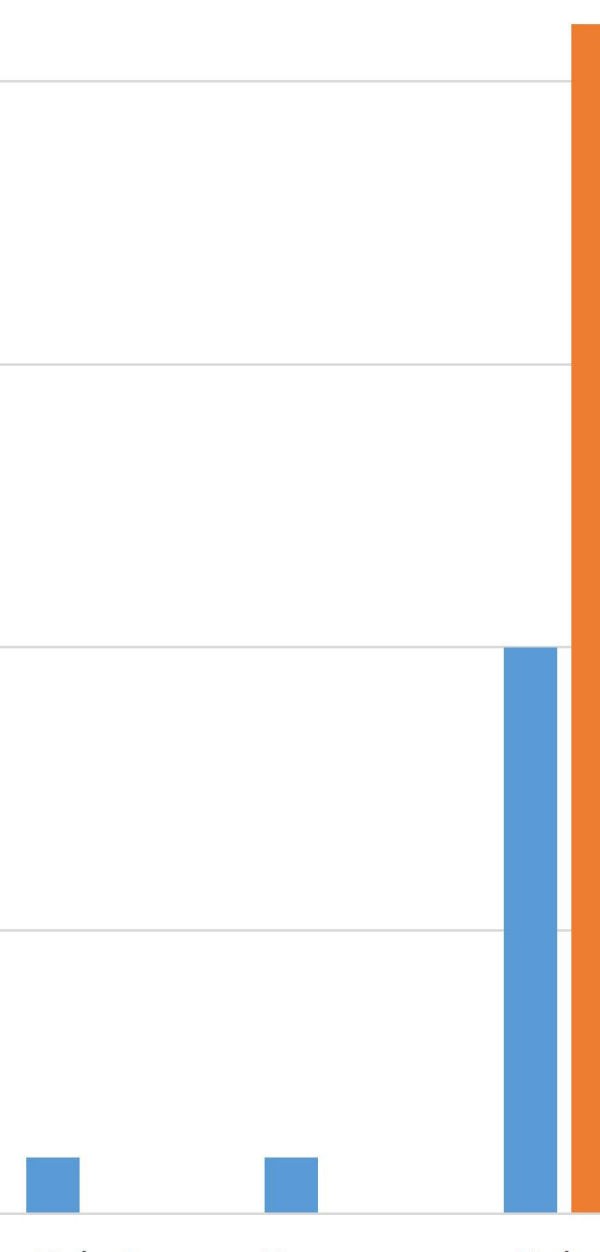

Hebei Province
Henan Province

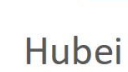

Province

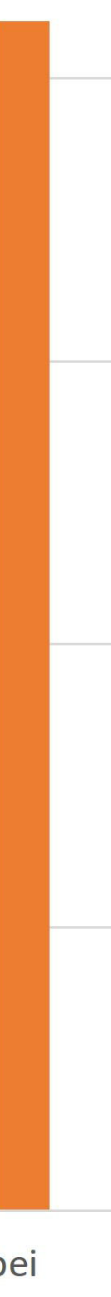

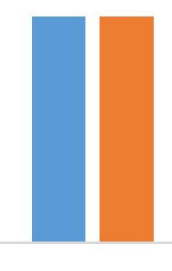

Hunan province
Jiangsu Province
Liaoning Province

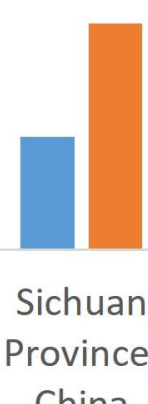

China

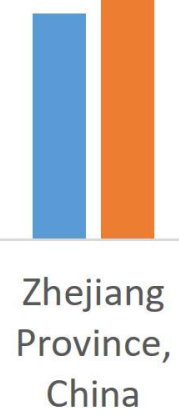




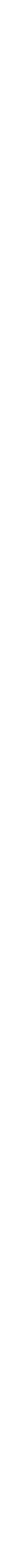




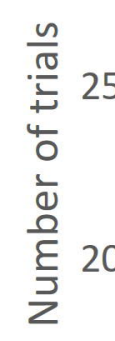

15

10

5

0
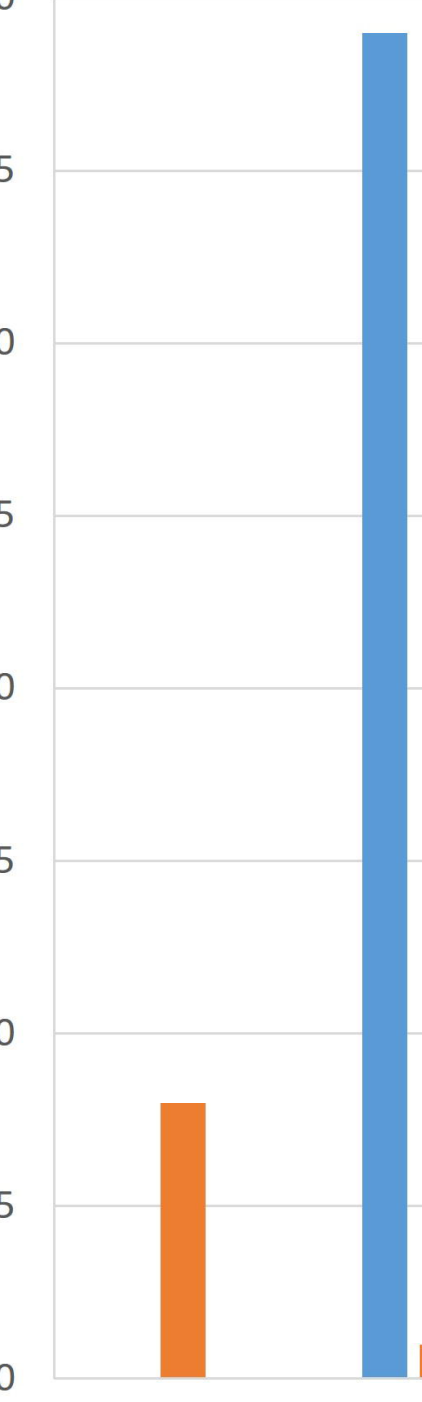

1

2

3

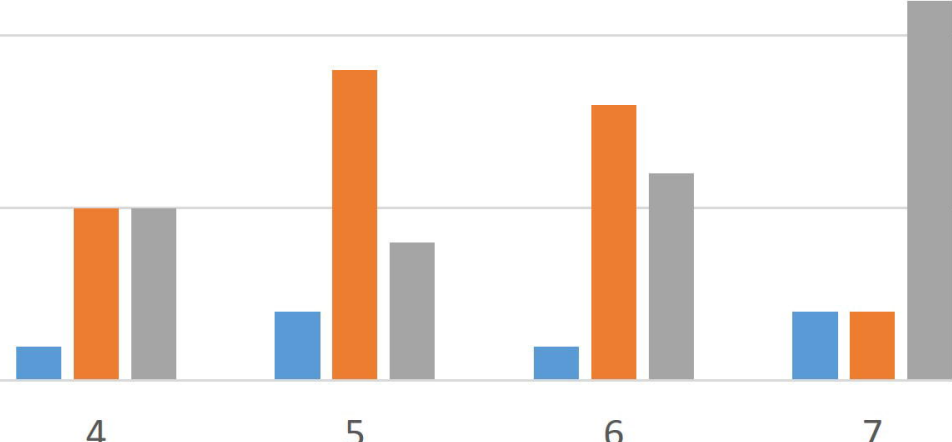

Number of outcomes 
-

है

20

10

0

1

2

3

4

5

6

Times of reporting 


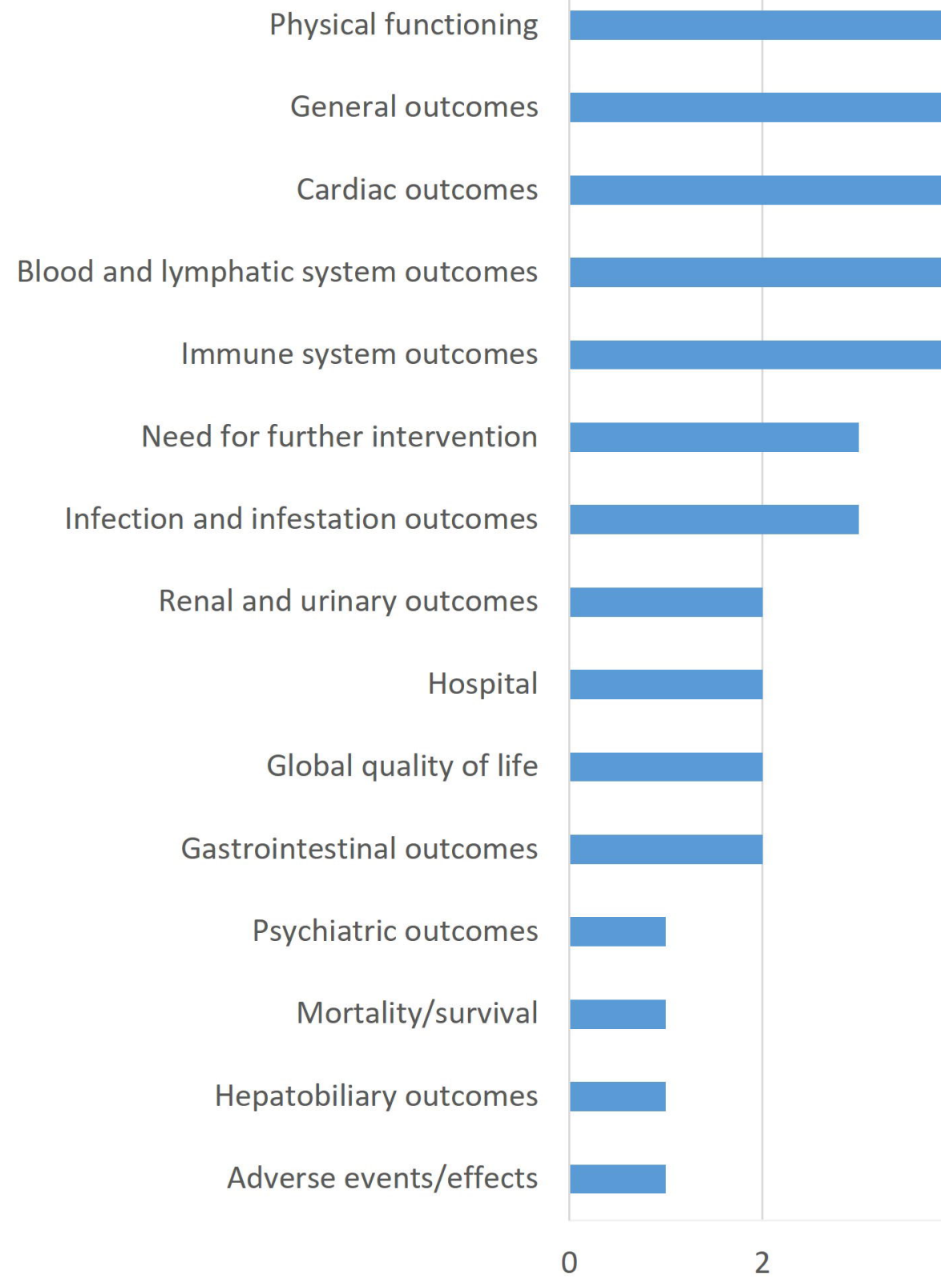

0 


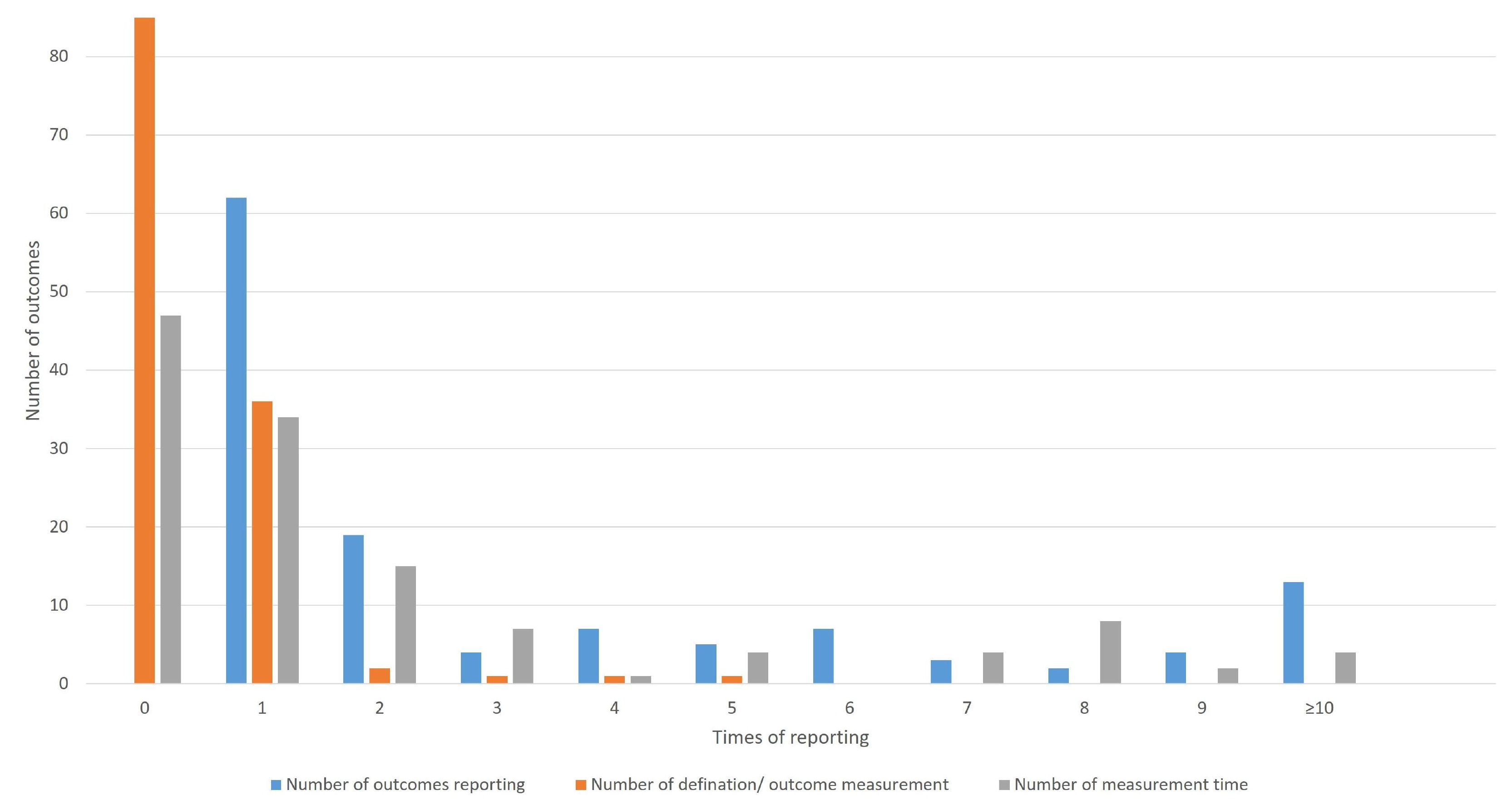


Physical functioning

Immune system outcomes

General outcomes

Infection and infestation outcomes

Cardiac outcomes

Blood and lymphatic system outcomes

Hospital

Need for further intervention

Renal and urinary outcomes

Hepatobiliary outcomes

nnective tissue outcomes

Mortality/survival

Metabolism and nutrition outcomes

Economic

Delivery of care

Adverse events/effects 